\title{
MUJERES LATINOAMERICANAS EN EL MERCADO LABORAL DE ANTOFAGASTA DURANTE EL CICLO SALITRERO, 1880-1930
}

\author{
José Antonio González Pizarro², Marcelo Lufin Varas ${ }^{3}$ y Claudio Galeno Ibaceta ${ }^{4}$
}

\begin{abstract}
Durante el auge del ciclo salitrero, la región de Antofagasta tuvo un crecimiento económico y demográfico superior a la media nacional. Dentro de este proceso, recibió un fuerte flujo migratorio latinoamericano. Las mujeres fueron parte significativa de este contingente inmigratorio. Nos interesa destacar de la presencia de peruanas, bolivianas y argentinas cuatro aspectos que dicen relación con la sociedad regional: a) Patrones de nupcialidad, que nos permitirá señalar el grado de exogamia o endogamia de los grupos estudiados; b) Procedencia geográfica de las mujeres migrantes en la zona en estudio; c) Sus ocupaciones principales y formas de inserción en mercado laboral; d) Estructuras familiares, mediante la identificación de grupos familiares migrantes y en la identificación de la forma en que se realizó el proceso migratorio.
\end{abstract}

Palabras claves: Argentinas - bolivianas - peruanas - salitre migración.

\begin{abstract}
During the boom of the nitrate cycle, Antofagasta Region showed an economic and demographic growth higher than the national mean. In this process, it received a strong Latin American migration flow. Women were a significant part of this immigration contingent. We are interested in highlighting four aspects of the presence of Peruvian, Bolivian, and Argentinian women, which are related to regional society: a) Marriage patterns indicating the extent of exogamy or endogamy of the studied groups; $b$ ) Geographic origin offemale migrants in the zone studied; $c$ ) Their main occupation and forms of integration in the labor market; d) Family structures, through the identification of migrant family groups and the way the migrant process occurred.
\end{abstract}

Keywords: Argentinians - Bolivians -Peruvians - nitrate - migration.

Recibido: julio 2015. Aceptado: abril 2016.

1 Forma parte del proyecto FONDECYT 1130785 año 2015.

2 Centro de Estudios Histórico-Jurídicos de la Facultad de Ciencias Jurídicas de la Universidad Católica del Norte, Casilla 1280 Antofagasta, CHILE.Email: jagonzal@ucn.cl

3 Departamento de Economía, Facultad de Economía y Administración de la Universidad Católica del Norte, Casilla 1280 Antofagasta, CHILE. Email: mlufin@ucn.cl

4 Escuela de Arquitectura de la Universidad Católica del Norte, Casilla 1280 Antofagasta, CHILE. Email: cgaleno@ucn.cl

\section{* La mujer latinoamericana durante la épo- CA DEL LIBERALISMO ECONÓMICO Y LA LIBER-}

TAD DE MIGRAR

Las mujeres latinoamericanas que migraron hacia la región de Antofagasta durante el auge salitrero presentaron diferencias en cuanto a su inserción en el mercado laboral como a su integración en la sociedad regional. Y ellas reflejaron los cambios verificados en sus países de procedencia, Bolivia, Perú y Argentina.

Nos interesa aproximarnos al modo en que las mujeres de las naciones mencionadas se vincularon con el mercado laboral y en cierta manera su inserción se vio favorecida por su relación de integración con la sociedad regional. No necesariamente hubo una acción mecánica entre ambos acoplamientos. De allí la necesidad de examinar los factores que hicieron posible su inserción en el mundo del trabajo - desde su capital social hasta el mundo de sus relaciones sociales - como de aquellos que permitieron su inserción en la región, principalmente mediante patrones de nupcialidad. Factores que refieren de sus lugares de procedencia y de la constitución de proyectos individuales o colectivos vinculados a estructuras familiares que posibilitan la formación de redes y sus nexos con su propia comunidad o con la vida social nativa.

Determinados autores (Bértola y Williamson 2003; Marichal 2011; Bértola y Ocampo 2013) han planteado para el período temporal que nos interesa, entre $1880-$ 1930, que se dieron cita tres factores relevantes, el incremento del comercio internacional, el aumento de los flujos de capitales y el alza de las migraciones masivas. Aquéllos modelaron el proceso de globalización 
del liberalismo decimonónico. En las naciones latinoamericanas, los rasgos de esta globalización convergieron con los cambios político-institucionales derivados de las reformas económicas liberales junto con la consolidación de las estructuras de poder político. Elementos que modificaron la fisonomía de los países en referencia, como también de Chile, como receptor, afectando asimismo las estructuras microsociales, principalmente de la familia. Las migraciones europeas masivas favorecieron a Brasil y Argentina y sus políticas de colonización, que ayudaron a consolidar sus procesos iniciales de industrialización. ${ }^{i}$

En general, la migración libre que se verificó entre 1880 hasta el fin de la Primera Guerra Mundial, produjo consecuencias contradictorias: por un lado, como ha enfatizado O'Rourke, constituyó un camino efectivo en los países pobres para mejorar el estándar de vida, un proceso autolimitado que produjo efecto en la distribución interna de los ingresos, tanto del país de origen como en el país receptor (O'Rourke 2004) y, por otro, el factor inmigratorio tendió a reducir los salarios reales en los países receptores (Hatton-Williamson 2006). El período se caracterizó por la hegemonía de la libertad comercial y de la movilidad libre, a pesar de las voces que solicitaban desde las naciones receptoras una selectividad en la inmigración, más calidad que cantidad, que se manifestó en los Estados Unidos y en países de América del Sur como una expresión nacionalista ( $\mathrm{O}^{\prime}$ Rourke 2004; Hatton-Williamson 2006; Solberg 1970).

Si bien se ha hecho notar que la inmigración europea debió sortear bastantes vallas de índole política, mercado laboral, los altos costos de pasajes, factores climáticos adversos y rasgos culturales y políticos poco atractivos (Sánchez 2007); el proceso migratorio femenino, en menor escala que el masculino, que se observó desde los países vecinos de Chile debió esquivar no pocos obstáculos, en pos de insertarse en el mercado laboral o vincularse más estrechamente con la sociedad regional, mediante un patrón de nupcialidad y de residencia en la región de Antofagasta.

Para comprender las historias individuales, dentro de los flujos migratorios femeninos hacia el norte chileno, la necesidad -o la exigencia disciplinaria- por visibilizar los mundos subjetivos y sociales de cientos de mujeres que la historia, como ha recalcado Bourdieu, de situar "los mecanismos históricos responsables de la deshistorización y de la eternización relativas de las estructuras de la división sexual y de los principios de división correspondientes" (Bourdieu 2000: 8).

Dentro de ese campo, las nociones usadas, el lenguaje empleado constituyen pistas del significado que tuvieron para la construcción de una sociedad que no consideró la dimensión de género como algo de importancia (Scott 1987). La pérdida del significado también contribuye a la deshistorización, que refiere Bourdieu. Dentro de esa semántica habrá que situar la devaluación del trabajo femenino, al no recibir una remuneración tanto en las actividades domésticas como en los trabajos en la agricultura, estimados más bien como "ayuda". Con el avance del capitalismo, desde el siglo XVIII, un factor importante ha sido la separación entre el "trabajo" y el "empleo", y como ha apuntado Nicky Le Feuvre, va a invisibilizar el trabajo femenino doméstico (Le Feuvre 1997) y la constatación de la devaluación de este trabajo en la contabilidad nacional, por otro, constituyendo la denominada "paradoja de Pigou", en honor al economista Arthur Cecil Pigou (Marín 2003).

La literatura especializada ha establecido las condiciones que debió abordar el mundo femenino en el período que nos ocupa.

La situación de las mujeres latinoamericanas durante los años 1880-1930 está enmarcada en un predominio más tradicional en cuanto al rol a jugar por la mujer, que se traduce en la continuidad de la mentalidad masculina sobre el papel de ésta en el ámbito privado.

Durante el siglo XIX y principios del XX, se consideraba que la institución familiar era natural: la creencia de que las esposas eran naturalmente dependientes de sus maridos, donde el hombre fijaba el domicilio de su cónyuge y su poder alcanzaba lo financiero -el mantenimiento de todos bajo su potestad, incluidas la propiedad de su mujer- y era el que tomaba las decisiones. Cuando la familia mostró disfuncionalidades, se consideró que la teoría del laissez faire, o sea la no intervención del Estado en el orden familiar, no daba respuestas adecuadas para amparar a los que estaban bajo la tutela patriarcal: el Estado debió normar, introduciendo leyes que limitaban la consideración natural (Olen 1999). 
En América, la familia exhibió modelos diversos en consonancia con la realidad social en que se inscribía su entorno nacional. De acuerdo a las influencias de determinadas naciones, más avanzadas en pro de la autonomía femenina, se pudo constatar cierta libertad de la mujer en escoger al cónyuge, en contraste con la búsqueda y traslado de la futura cónyuge desde el Viejo Mundo. Hubo un número importante de personas que nunca se casaron, o tuvieron hijos ilegítimos, realidad común en el Nuevo Mundo (García y Guarda 2002).

Como se ha hecho notar, el pensamiento liberal no solamente influyó en la economía sino que confluyó con el modelo patriarcal, estableciendo dos esferas distintas, la pública y la privada, con funciones y roles opuestos para mujeres y hombres (Pateman, 1996). Se estimaba que la mujer debía cuidar el hogar, la crianza, mientras el hombre debía ir en procura de la manutención en el mercado laboral. La resistencia por la participación de la mujer en el mundo laboral se argumentaba en asignar dicha presencia como la causa de la baja tasa de natalidad, la mortalidad infantil, la dispersión familiar y la renuncia paterna por la orientación de los hijos (Lagrave 2000).

La importancia de la patria potestad, eje estructurador del orden doméstico, ha sido destacada por Rossana Barragán, como la noción que articula la distinción entre los hombres y entre hombres y mujeres y entre las mujeres honradas y de buena fama en contraposición a las mujeres corruptas y prostitutas, y de la filiación legítima e ilegítima- que otorga forma al espacio familiar y también a la nación (Barragán 1997). Esto pudo haber incidido en la preocupación de la mujer hacia el cuidado de sus hijos, la organización del consumo familiar y a la cotidianidad del hogar (Acuña 2010). Esta visión fue reforzada por la educación formal orientada por la cultura dominante masculina que construyó socio y culturalmente la "naturalización" de las diferencias de los sexos, para fundamentar la dominación de un sexo sobre otro (Dora Barrancas, citada en Peruso 2006: 16). La argumentación naturalista llegaba a expresar, en el campo pedagógico, que la concepción anatómica del cuerpo de la mujer era fundamento de su irracionalidad (Pedraza 2011). En esa instrucción sesgada del género se hizo "hincapié en la aguja, no en la pluma" y así los esfuerzos educacionales apuntaron a la necesidad de educar adecuadamente a la mujer para gobernar su casa, criar a sus hijos y hacer feliz a su marido (Mora 1993). Orientaciones que se encuentran en las naciones de donde proceden las mujeres en estudio, Argentina, Bolivia y Perú (Gonzalbo 1999). En el proceso formativo, se va a inculcar lo que Asunción Lavrin va a denominar el "síndrome de la gran mujer", consistente en redimir el anonimato de muchas mujeres mediante el brillo de unas cuantas (Lavrin 1985). O lo que se va a calificar como "el efecto espejo": la mujer se vuelve notable por participar en algún acontecimiento masculino o por una relación amorosa (Ramos 1984). El espacio público dominado por la política quedó muy restringido, principalmente para los inmigrantes por la sospecha policial sobre actividades ilícitas. Prueba de ello, para el caso de Chile, fue la ratificación del Convenio Policial de Buenos Aires de 1906 y el levantamiento de los prontuarios de extranjeros que hemos usado en este trabajo. Y esto en razón de la recepción de las ideas anarquistas que en Argentina abogaban por la liberación de la mujer (Barrancos 2008; Valle 2004) o por la difusión del ideario socialista en Argentina (Bonilla 2007), en Perú (Guardia 1995) y en Bolivia (Rodríguez 2007).

Si nos aproximamos al factor del capital social en la condición de la mujer, se puede indicar que las sumidas en la pobreza, analfabetas, marginales en su trabajo, vieron agravadas su situación en la ancianidad, viudez o la enfermedad y en épocas de crisis económicas (Castro 1997). La prostituta simbolizó la descomposición social en las arterias citadinas, mientras el discurso médico desenvolvió una política higienista que vinculó lo femenino a lo patológico, aplicando políticas eugenésicas a partir de la década de 1920 (Mannarelli 1999; De Liscia 2006). En contraste con esta realidad, las mujeres de la burguesía lograron de modo excepcional ingresar a la universidad, canalizándose en profesiones como el magisterio (principalmente normalista), la medicina, casi simultáneamente a su incorporación en Europa. En Chile, Eloísa Díaz, en 1887, fue la primera doctora en medicina de América del Sur, seguida por una Argentina, todas en la década de 1880. Se ha estimado que la medicina era una carrera profesional "apropiada" para ellas, pues la mujer desenvolvía el rol de "supervisora de la salud y las enfermeras del hogar" (Itati 2006: 19), al igual que la prolongación de "las funciones domésticas" abarcaban la enseñanza, servicios y los cuidados (Bourdieu 2000; Marrero 2006). 
La situación del trabajo femenino en América Latina en el lapso temporal que hemos definido se vio alterada por los cambios suscitados por el impacto del proceso de industrialización, los cambios en áreas económicas primarias, los flujos migratorios internos, desde el campo hacia la ciudad. En la ciudad, los talleres y las fábricas abrieron posibilidades de nuevos trabajos a las mujeres. Algunos autores (Cerna et al. 1997: 27) han planteado el tránsito desde las "agujas" de la casa a las de manufacturas y textiles "de aguja", el trabajo mecanizado femenino, creando, por ejemplo, en Perú "cadenas de solidaridad". Empero, la incorporación de la mujer en el mercado urbano, principalmente en el área de servicios, fue ignorada en los censos o bien provocó la "marca de la baja legitimidad de las tareas" (Barrancos-Cano 2006: 500).

En la realidad de las mujeres latinoamericanas gravitó, además de la división sexual del trabajo, la diferenciación étnica, principalmente de la distinción entre indígenas/ mestizas/blancas. Esta constatación fue más manifiesta en los trabajos rurales, como proyección de la herencia colonial y se verificó en las actividades urbanas, vinculando lo étnico/iletrado/capital social no cualificado, que la literatura nacional específica ha establecido (cf. Van Deusen 2002; Soruco 2012).

Si el capital social como las redes sociales fueron factores significativos en la incorporación de la mujer al mercado laboral, los patrones de nupcialidad determinaron un fuerte indicador de su inserción en la sociedad regional, al enunciar los grados de endogamia y exogamia. Los elementos reseñados a su vez se vieron influenciados por la procedencia geográfica y las estructuras familiares que coadyuvaron a la migración. Sin olvidar que el grado de masculinidad oriunda condicionó el volumen de la migración femenina.

En los casos de migrantes de estudio, se puede indicar que los rasgos predominantes de la inmigración femenina se enmarcaron en un contexto de hegemonía de la migración masculina e individuos jóvenes que en general eran solteros y vivían próximos a la frontera chilena. De allí la poca atención brindada a la migración femenina latinoamericana de inicios del siglo XX, según ha examinado Ramiro Flores (2003).

La presencia femenina extranjera de países vecinos en la región de Antofagasta, fue el resultado de un doble pro- ceso de cambio espacial, desde la migración interna, del campo a la ciudad, y de una migración transfronteriza, de un país a otro, derivado de varios factores, entre otros, modificaciones político-administrativas (la anexión de la Puna occidental a la República Argentina conformando inicialmente el Territorio de los Andes y posteriormente incorporándose a las provincias de Jujuy, Salta y Tucumán; el traslado de la capital desde Sucre a La Paz en el caso de Bolivia; los cambios territoriales, p.e. Tacna, entre Chile y Perú, etc.) o cambios económicos, como fueron el afianzamiento del eje minero Oruro-Potosí mediante la red ferroviaria y el nuevo ciclo minero del estaño y la desaparición de las comunidades indígenas (Klein 1992, 1983). En el caso de Perú, la conectividad ferroviaria no dio lugar a un mercado nacional sino por el contrario a economías regionales. En Argentina, se asistió a las transformaciones de la tenencia de la tierra por impacto de la colonización en desmedro de la población nativa en el noroeste de la república. Empero, desde la perspectiva demográfica, encontramos amplias disimilitudes entre los tres países. Argentina es el país que recibe el mayor volumen de inmigrantes europeos en América Latina, que incidió en su estructura productiva y poblacional, a partir de 1885. En el lapso de 1885-189o, el aumento inmigratorio superó al crecimiento vegetativo y entre 1905-1910 se concentró el mayor volumen de extranjeros (Cortés 1992; Gallo 1992; Recchini de Lattes y Lattes 1974; Flores s.d.). De las regiones de donde procedió la migración argentina, a excepción de Buenos Aires, la mayoría exhibió una constante disminución, como lo consignaron los censos de 1895 y 1914: Catamarca de un 2,3 a 1,3 millones, Salta desde 3,0 a 1,8 millones y La Rioja, de un 1,7 a 1,0 millones. En tales espacios geográficos, se mantuvo el predominio de la población rural y la merma demográfica no se pudo compensar con la influencia inmigratoria masiva, que no se manifestó en el noroeste argentino (Pizzolito 2006). La población argentina del noroeste fue casi insignificante ante las regiones de Buenos Aires y de las pampas, donde se albergaba hacia 1914 el 73,6\% de la población total (Devoto y Fausto 2004: 152)

En Perú, la distancia temporal entre el censo de 1876 y el verificado en 1940 imposibilita inferir los cambios demográficos en las regiones desde donde provino la migración hacia Antofagasta (Cosamalón 2011). Se sabe que la población de la sierra era prevaleciente sobre la asentada en la costa y se conjetura cierta equiparidad entre 
hombres y mujeres. Los datos estadísticos parciales de 1896 y 1927 tampoco logran aportar tendencias demográficas sobre Lima, Arequipa, Callao, Mollendo o Tacna (Monsalve 2011; Klaren 1992).

Respecto de Bolivia, la proximidad de la frontera hizo de Potosí la principal región que aportó cerca de la mitad del contingente femenino, validando una de las leyes de Ravenstein acerca de que las distancias cortas hacen posible la migración de las mujeres (González 2010). El censo de 1900, en Bolivia, mostraba el predominio de la población rural en el país (de un total de 1.696.000 habitantes, la población urbana correspondía a 457.920 personas, es decir solo a un 27\% del total (Soliz 2014; Norris 2001), especialmente en los departamentos que aportaron los contingentes migratorios hacia Chile. Potosí con 325.615 habitantes mientras la capital del departamento tenía 20.910 habitantes; Cochabamba con 326.163 habitantes y su capital con 21.881 personas. La Paz superaba el porcentaje de habitantes en la capital respecto al departamento ( $52.697 / 426.930)$, de igual modo Oruro ( 13.575 / 86.081). Potosí y Oruro mostraban la faceta de modernización de la república altiplánica, cuando todavía la población total de Bolivia exhibía en el censo de 1900 un $80 \%$ de analfabetos (Mesa y Gisbert 1998).

En cuanto a la presencia latinoamericana durante el denominado ciclo salitrero, se ha establecido que la industria del caliche tanto en Tarapacá como en Antofagasta constituyó un polo de atracción para la migración transfronteriza (González Miranda 2009; Tapia 2014; González Pizarro 2010). Las conductas de la población femenina latinoamericana, en este caso de los contingentes de bolivianas, peruanas y argentina en Tarapacá, mostraron una forma de integrarse a la sociedad regional mediante su patrón de nupcialidad, siendo los índices de argentinas un $86,5 \%$ de exogamia, seguidas de bolivianas con un $65,9 \%$ y finalmente las peruanas con un 51,2\% de enlaces matrimoniales con chilenos (Calle 2008).

Las modificaciones en el mundo de la mujer latinoamericana (educación, movimiento de ideas, estructura familiar y trabajo), también se hicieron presente en Chile (cf. Mauro et al. 2009; Sagredo y Gazmuri 2006).

Cabe acotar que Chile mostraba una de las tasas de mortalidad infantil más altas hacia 1920 y en gran medida la ciudad de Antofagasta pudo paliar con la inmigración el débil crecimiento de su población, pues, como afirmara Klein, las ciudades portuarias justifican de este modo su alza poblacional (Klein 2011).

\section{* Antecedentes históricos y contexto del CASO DE LOS/AS MIGRANTES EN LA PROVINCIA DE ANTOFAGASTA}

La región de Antofagasta pasó al dominio chileno a partir de la ocupación de Antofagasta en 1879, hecho que dio lugar a la llamada Guerra del Pacífico que confrontó a Chile contra la alianza de Perú y Bolivia. Como consecuencia de este conflicto la frontera de Chile se expandió hacia el norte (Sicotte et al. 2009). Esta expansión territorial también se asocia a una ampliación económica de fuerte base sectorial, debido a la intensificación de la actividad minera no metálica asociada a la industria del nitrato.

La forma en que se realiza este desarrollo es inédita en cuanto se trata del ensanchamiento de un territorio con bajísima densidad poblacional, que se ocupa y se construye prácticamente en una modalidad de tierra vacía. Cabe indicar que en la perspectiva demográfica, la población mayoritaria distribuida en la costa y en los asientos mineros, anterior a 1879 , era chilena. Un proceso migratorio que había comenzado con la creación del puerto Lamar en 1825 , donde el peonaje chileno, a mediados del siglo XIX, ya era el predominante (Pinto y Valdivia 1994). Tal rasgo se verificó también en Antofagasta. El censo levantado en 1875 ya nos refiere de una sociedad plural, donde el elemento más significativo era el chileno -4.530 personas de un total de 5.384 habitantes-, donde la proporción entre hombres y mujeres refería de 3.028 hombres y 2.356 mujeres (Rojas 2012: 277). La presencia de varias nacionalidades en Antofagasta se refrenda en el censo levantado en 1878 , donde de un total de 8.507 habitantes, 6.554 eran chilenos, 1.226 bolivianos, 226 argentinos, 121 peruanos, entre las colonias más importantes, no faltando los segmentos europeos: 104 ingleses, 47 españoles, 40 franceses, 35 italianos, 32 alemanes, etcétera (Hernández 1930: 96).

Se ha hecho notar que la bajísima densidad demográfica acompaña los procesos económicos asociados a las modalidades de inversión, que en este caso se caracterizarán por una fuerte participación de capitales extranjeros 
y sectores locales de avanzada, por la introducción de nuevas prácticas de trabajo y de organización de la producción, por patrones de propiedad de los medios de producción diferentes, pues en muchos de ellos se estrenan conductas similares a la moderna modalidad del "joint venture" y por supuesto por la introducción de nueva tecnología aplicada. Particularmente, durante el denominado ciclo histórico del salitre, 1880-1930, que hegemonizó la tecnología Shanks de producción. En este escenario lo peculiar fue la profundización de la integración mundial de los mercados de materias primas ("commodities"), las migraciones internacionales a gran escala ( $\mathrm{O}^{\prime}$ Rourke 2004), derivadas de cambios tecnológicos en la industria del transporte y las comunicaciones (Bértola-Williamson 2003), y a la caída de las barreras al comercio internacional, como fenómenos paralelos a la industrialización de Europa y del este de los Estados Unidos (Williamson 2002). Adicionalmente, a este período se le atribuyen el surgimiento de las modernas compañías transnacionales, procesos extensos de concentración de capital, la formación del sistema financiero internacional y un creciente aumento en la movilidad del capital y el trabajo (Ortega y Venegas 2005).

Sin embargo, desde una perspectiva institucional y demográfica, se debe indicar que la región de Antofagasta fue creada como provincia en 1888, agregándosele a ella el territorio del departamento de Taltal, amputándolo a la provincia de Atacama, lo cual se tradujo que en el censo de 1885 la población de Taltal no figurara en el entonces Territorio de Antofagasta (González 2010a). Para examinar la importancia de la población migrante en estudio, en la Tabla 1 se presenta una síntesis de la información disponible en los Censos de Población para el país de los años $1895,1907,1920$ y 1930.5

En primer lugar en la Tabla 1, debe destacarse la expansión de la población en la provincia, que entre 1895 y 1930 prácticamente se multiplica por cuatro, lo que muestra la importancia de la nueva frontera norte en el proceso de ampliación del país. Otro elemento distintivo es la masculinización de esta población, con razones entre población masculina y femenina del orden de 1:5 en promedio

5 Pese a las limitaciones de los datos, también se ha incluido en la Tabla 1 alguna información disponible para el Censo de 1885, con el propósito de visibilizar las magnitudes demográficas al inicio del período de estudio. para el período, lo que implica la existencia de tres hombres por cada dos mujeres en la provincia, característica fundamentalmente asociada al tipo de actividad y forma de organización productiva en la región.

Con relación a la presencia de población extranjera, la provincia de Antofagasta presenta tasas elevadas, alcanzando un máximo del 19\% en 1907 para los hombres y un $12 \%$ para las mujeres en 1895 . Estos valores son considerablemente más altos que en la situación promedio del país, solo similares a las condiciones existentes en la región de Tarapacá que vivió un proceso histórico parecido (Tapia 2012), pero con una composición relativa distinta puesto que en el caso de la provincia de Antofagasta estos grupos se complementaron con un importante contingente de inmigrantes europeos, ingleses, alemanes y ciudadanos austrohúngaros (particularmente croatas).

Para explorar y describir las condiciones de instalación de la población inmigrante de los países limítrofes en este caso, se ha optado por utilizar indicadores clásicos de patrones de localización puesto que presentan la ventaja de relativizar la situación de la provincia en función de la tendencia dominante en el país.

Retornando a los resultados de la Tabla 1, las condiciones específicas de atracción hacia la provincia de Antofagasta para los grupos inmigrantes de interés (argentinos/as, bolivianos/as y peruanos/as), queda potentemente descrita por los respectivos índices de localización. Éstos denotan una localización importante para el caso boliviano y argentino y menor medida para el peruano; además estos patrones son mucho mayores en hombres que en mujeres, situación consistente con la masculinización típica ya asociada a la provincia y su sistema productivo minero y las formas de migración dominantes en el contexto histórico.

Para efectos de claridad metodológica para el estudio de los patrones de localización, se ha considerado la utilización de coeficientes de localización ${ }^{6}$ propuestos por

6 Los coeficientes de localización tienen la siguiente forma: $\mathrm{CLi}=(\mathrm{Pij} / \mathrm{Pi}) /(\mathrm{Pj} / \mathrm{PN})$ Donde: $\mathrm{CLi}$ indica el exceso de probabilidad de encontrar un inmigrante, originario de "i”, en el la localización en estudio como proporción de la probabilidad de encontrar un inmigrante " $i$ " en el país. Estos indicadores de localización son idénticos en su formulación matemática a 


\begin{tabular}{|c|c|c|c|c|c|c|c|c|c|c|}
\hline \multirow[b]{2}{*}{ Provincia } & \multicolumn{2}{|c|}{ Censo $1885(1)$} & \multicolumn{2}{|c|}{ Censo 1895} & \multicolumn{2}{|c|}{ Censo 1907} & \multicolumn{2}{|c|}{ Censo 1920} & \multicolumn{2}{|c|}{ Censo 1930} \\
\hline & Hombres & Mujeres & Hombres & Mujeres & Hombres & Mujeres & Hombres & Mujeres & Hombres & Mujeres \\
\hline $\begin{array}{l}\text { Total Población Provincia } \\
\text { de Antofagasta }\end{array}$ & 12578 & 8635 & $26039(2)$ & 18046 & $71846(3)$ & 41477 & $99491(4)$ & 72839 & $101412(5)$ & 77353 \\
\hline $\begin{array}{l}\text { Total Población Extranjera } \\
\text { Provincia de Antofagasta }\end{array}$ & \multicolumn{2}{|c|}{6519} & 4049 (6) & 2141 & $13805(7)$ & 3995 & $10813(8)$ & 4909 & $8232(9)$ & 3497 \\
\hline $\begin{array}{c}\text { Población Extranjera como } \\
\% \text { Población Total de } \\
\text { Provincia de Antofagasta }\end{array}$ & \multicolumn{2}{|c|}{$30,7 \%$} & $15,5 \%$ & $11,9 \%$ & $19,2 \%$ & $9,6 \%$ & $10,9 \%$ & $6,7 \%$ & $8,1 \%$ & $4,5 \%$ \\
\hline $\begin{array}{c}\text { Total Población Extranjera } \\
\text { como \% Población Total } \\
\text { en Chile }\end{array}$ & \multicolumn{2}{|c|}{$3,4 \%$} & $3,9 \%$ & $2,0 \%$ & $5,7 \%$ & $2,6 \%$ & $4,4 \%$ & $2,2 \%$ & $3,2 \%$ & $1,7 \%$ \\
\hline $\begin{array}{l}\text { Total Población Boliviana } \\
\text { Provincia de Antofagasta }\end{array}$ & S/D & S/D & $1228(10)$ & 1268 & $3555(11)$ & 2273 & $3866(12)$ & 2768 & $2718(13)$ & 1997 \\
\hline $\begin{array}{c}\text { Bolivianos como \% } \\
\text { Población Extranjera Total } \\
\text { en Provincia }\end{array}$ & S/D & S/D & $30,3 \%$ & $59,2 \%$ & $25,8 \%$ & $56,9 \%$ & $35,8 \%$ & $56,4 \%$ & $33,0 \%$ & $57,1 \%$ \\
\hline $\begin{array}{l}\text { Total Población Argentina } \\
\text { Provincia de Antofagasta }\end{array}$ & S/D & S/D & $733(10)$ & 387 & $1111(11)$ & 67 & 949 (12) & 382 & $470(13)$ & 236 \\
\hline $\begin{array}{c}\text { Argentinos como \% } \\
\text { Población Extranjera Total } \\
\text { en Provincia }\end{array}$ & $\mathrm{S} / \mathrm{D}$ & S/D & $18,1 \%$ & $18,1 \%$ & $8,0 \%$ & $1,7 \%$ & $8,8 \%$ & $7,8 \%$ & $5,7 \%$ & $6,7 \%$ \\
\hline $\begin{array}{l}\text { Total Población Peruana } \\
\text { Provincia de Antofagasta }\end{array}$ & S/D & S/D & $217(10)$ & 241 & $1194(11)$ & 555 & $108(12)$ & 174 & $164(13)$ & 127 \\
\hline $\begin{array}{c}\text { Peruanos como \% } \\
\text { Población Extranjera Total } \\
\text { en Provincia }\end{array}$ & S/D & S/D & $5,4 \%$ & $11,3 \%$ & $8,6 \%$ & $13,9 \%$ & $1,0 \%$ & $3,5 \%$ & $2,0 \%$ & $3,6 \%$ \\
\hline $\begin{array}{l}\text { Total Población Chile } \\
\text { (14) }\end{array}$ & \multicolumn{2}{|c|}{2.527 .320} & \multicolumn{2}{|c|}{2.695 .911} & \multicolumn{2}{|c|}{3.231 .496} & \multicolumn{2}{|c|}{3.731 .573} & \multicolumn{2}{|c|}{4.287 .445} \\
\hline
\end{tabular}

Notas y Fuentes: Publicaciones impresas de los Libros de Censo de Población y Vivienda 1885, 1895, 1907, 1920 y 1930. Memoria Chilena, http://www.memoriachilena.cl/602/w3-article-31530.html.

Tabla 1. Importancia relativa de población extranjera migrante.

Isard (1971). Los resultados de estos indicadores (Tabla 2), han sido calculados tanto a nivel de la provincia, como del departamento de Antofagasta. Dichos resultados indican que en esta provincia sistemáticamente es más probable encontrar extranjeros que en el resto del país, lo que implica un patrón altamente localizado. En promedio esta probabilidad excede para el período 1895-1930 casi 4 veces la situación nacional comparada

los utilizados para medir excesos de riesgo (Isserman 1977) y representan si su valor es 1 , que es igualmente probable encontrar a un migrante "i" en la provincia que en el país, si su valor es menor que 1 , implica que es menos probable encontrar un migrante " $i$ " en la provincia de lo que es posible en el país y si es mayor que 1 , que es mucho más probable encontrar un migrante "i" en la provincia que en el país. para el caso de los hombres, y para las mujeres es de 3.1 veces la posición nacional.

Cuando se controlan por los grupos nacionales específicos, la situación tiende a cambiar un poco en el caso de los peruanos, quienes aparecen relativamente menos localizados en la provincia que bolivianos y argentinos. En términos comparativos los hombres aparecen menos intensamente localizados en la provincia que las mujeres (para 1895, 1920 y 1930), salvo en el caso argentino en el que ellas presentan una menor conexión relativa con la provincia. Esta mayor localización de las mujeres puede ser reflejo de que sus oportunidades de instalación en el extranjero están condicionadas a la presencia de familiares y conocidos en el área de destino, lo que hace que su 


\begin{tabular}{|c|c|c|c|c|c|c|c|c|}
\hline \multirow[b]{2}{*}{ Provincia } & \multicolumn{2}{|c|}{ Censo 1895} & \multicolumn{2}{|c|}{ Censo 1907} & \multicolumn{2}{|c|}{ Censo 1920} & \multicolumn{2}{|c|}{ Censo 1930} \\
\hline & Hombres & Mujeres & Hombres & Mujeres & Hombres & Mujeres & Hombres & Mujeres \\
\hline $\begin{array}{c}\text { CLi Extranjeros en Provincia } \\
\text { Antofagasta }\end{array}$ & 4,0 & 6,0 & 3,4 & 3,7 & 2,5 & 3,1 & 2,5 & 2,6 \\
\hline $\begin{array}{c}\text { CL2 Bolivianos en Provincia } \\
\text { Antofagasta }\end{array}$ & 13,8 & 25,6 & 5,9 & 10,8 & 7,2 & 12,5 & 9,0 & 13,8 \\
\hline $\begin{array}{c}\mathrm{CL}_{3} \text { Argentinos en Provincia } \\
\text { Antofagasta }\end{array}$ & 7,5 & 11,4 & 5,7 & 1,0 & 4,0 & 3,3 & 2,6 & 2,0 \\
\hline $\begin{array}{c}\mathrm{CL}_{4} \text { Peruanos en Provincia } \\
\text { Antofagasta }\end{array}$ & 1,3 & 2,5 & 1,7 & 2,0 & 0,3 & 0,7 & 1,1 & 1,2 \\
\hline $\begin{array}{c}\mathrm{CL}_{5} \text { Extranjeros en Depto. de } \\
\text { Antofagasta }\end{array}$ & 5,0 & 8,1 & 4,2 & 4,7 & 2,9 & 3,9 & 2,7 & 2,8 \\
\hline $\begin{array}{c}\text { CL6 Bolivianos en Depto. de } \\
\text { Antofagasta }\end{array}$ & 23,6 & 40,3 & 8,6 & 15,9 & 9,5 & 16,6 & 0,9 & 1,7 \\
\hline $\begin{array}{c}\mathrm{CL}_{7} \text { Argentinos en Depto. de } \\
\text { Antofagasta }\end{array}$ & 8,7 & 7,5 & 1,9 & 1,6 & 1,5 & 1,8 & 0,4 & 0,6 \\
\hline $\begin{array}{c}\text { CL8 Peruanos en Depto. de } \\
\text { Antofagasta }\end{array}$ & 3,2 & 5,9 & 2,5 & 3,3 & 0,2 & 1,0 & 0,3 & 0,6 \\
\hline
\end{tabular}

Fuente: Elaboración propia con base a información de los Censos de Población y Vivienda de 1895, 1907, 1920 y 1930.

Tabla 2. Coeficientes de Localización ${ }^{7}$ para población extranjera en provincia y departamento de Antofagasta.

localización sea más concentrada como reflejo de estas condiciones de mayor control social que las afecta.

Profundizando un poco más en estos indicadores provinciales, se destaca que:

Para el caso de la población boliviana, tanto hombres como mujeres presentan índices de localización muy altos en la provincia de Antofagasta, con probabilidades relativas de localización que es de casi 9 y 16 veces la media nacional de su participación relativa para hombres y mujeres respectivamente, para todo el período considerado. Esta mayor presencia relativa no es extraña considerando la cercanía del país de origen a la localización y que se trata de un territorio que en el pasado formaba parte de esa misma nación.

La población argentina migrante, aunque en menor magnitud que en el caso boliviano, también presenta coeficientes elevados para dicho período, que en promedio ellos indican una probabilidad relativa de localización que son casi 5 y 4 veces mayores, para hombres y mujeres respectivamente, que la situación nacional.?

$7 \mathrm{CL} 1$, Coeficiente de localización de extranjeros en provincia de Antofagasta $=(($ Población Extranjera Total en provincia de Antofagasta/Población Total en provincia de Antofagasta)/(Población Extranjera Total en Chile/ Población Total en Chile)).

$\mathrm{CL}_{2}$, Coeficiente de localización de bolivianos en provincia de Antofagasta = ((Población Total de bolivianos en provincia de Antofagasta/Población Total de provincia de Antofagasta)/ (Población Total de bolivianos en Chile/ Población Total en Chile))

$\mathrm{CL}_{3}$, Coeficiente de localización de argentinos en provincia de Antofagasta $=(($ Población Total de argentinos en provincia de Antofagasta/Población Total de provincia de Antofagasta)/ (Población Total de argentinos en Chile/ Población Total en Chile))

$\mathrm{CL}_{4}$, Coeficiente de localización de peruanos en provincia de Antofagasta $=(($ Población Total de peruanos en provincia de Antofagasta/ Población Total de provincia de Antofagasta)/ (Población Total de peruanos en Chile/ Población Total en Chile))

$\mathrm{CL}_{5}$, Coeficiente de localización de extranjeros en departamento de Antofagasta $=(($ Población Extranjera Total en departamento de Antofagasta/ Población Total en departamento de Antofagasta)/ (Población Extranjera Total en Chile/ Población Total en Chile)).

CL6, Coeficiente de localización de bolivianos en departamento de Antofagasta = ((Población Total de bolivianos en departamento de Antofagasta/ Población Total en departamento de Antofagasta)/ (Población Total de bolivianos en Chile /Población Total en Chile))

$\mathrm{CL}_{7}$, Coeficiente de localización de argentinos en departamento de Antofagasta = ( (Población Total de argentinos en departamen - 
Finalmente, el caso peruano también presenta condiciones de localización en la provincia de Antofagasta, pero mucho menores que los dos grupos anteriores, solo llama la atención el caso de las mujeres peruanas que presentan una probabilidad de localización que en promedio es tres veces la situación nacional, pero solo hasta 1907; luego esta condición de localización se desvanece.

Otro elemento importante en la Tabla 2, son los coeficientes de localización calculados para el departamento de Antofagasta. Esta unidad administrativa es una unidad menor a la provincia y es la forma más adecuada para aproximar la situación de la comuna de Antofagasta que es parte del departamento del mismo nombre.

Los resultados a nivel departamental indican una fuerte localización de los grupos en estudio, pero este patrón cambia dramáticamente en el Censo 1930, donde se produce una literal deslocalización completa de la población extranjera en estudio, situación explicada por la profundidad de la Gran Depresión, escenario internacional que profundiza la crisis asociada al ciclo terminal de la industria del salitre.

Particularmente para el caso boliviano, la comparación entre los índices de localización provincial versus departamental, muestra una elevación del segundo en hombres y mujeres para los años 1895,1907 y 1920 . Esto indica que la población boliviana tendió a concentrarse en torno al departamento de Antofagasta, lo que estaría indicando un patrón de localización en torno a la mayor área urbana de la provincia, además su capital administrativa. Esta tendencia se interrumpe en 1930, cuando los indicadores señalan lo ocurrencia de lo contrario, es decir, que tanto bolivianos y bolivianas tienen una mayor presencia relativa fuera del departamento de Antofagasta. Esto -en el contexto de la crisis salitrera del período- podría asociarse a una intensificación relativa de localizaciones hacia la zona precordillerana y la ciudad de Calama, donde

to de Antofagasta/Población Total de departamento de Antofagasta)/ (Población Total de argentinos en Chile/ Población Total en Chile))

CL8, Coeficiente de localización de peruanos en departamento de Antofagasta $=(($ Población Total de peruanos en departamento de Antofagasta/ Población Total en departamento de Antofagasta)/ (Población Total de peruanos en Chile /Población Total en Chile)). se desarrolla la actividad agrícola de la región y la nueva actividad minera metálica asociada a la minería de cobre.

Los indicadores revelan que algo similar ocurre con las inmigrantes peruanas, quienes a pesar de su menor volumen relativo como flujo migratorio, presentan mayores índices de localización en el departamento por sobre la provincia, tendencia que se mantiene hasta 1907, año a partir del cual la intensidad de su localización en el departamento y provincia comienzan a reducirse hasta los mínimos de 1930.

Finalmente, las argentinas tienen un patrón de localización que es diferente, en general los indicadores en la provincia son mayores que los del departamento, circunstancia que pudiese estar asociada a que las mujeres argentinas tienen un espacio de localización más amplio y no necesariamente en la capital provincial. En este caso nuevamente los resultados para el 1930 señalan una situación de localización no intensiva de este conglomerado en el departamento de Antofagasta, hecho que nuevamente puede estar asociado a un desplazamiento de retorno a Argentina y/o a una relocalización interna en el país y en la provincia.

\section{* Modus Vivendi, la situación específica de LAS MUJERES MIGRANTES EN LA CIUDAD DE ANTOFAGASTA}

Tal como se reseña en la sección introductoria del documento, durante el siglo XIX y principios del XX, la situación de la mujer latinoamericana -como en otras latitudes- debe entenderse contenida en un sistema de relaciones sociales que limitan sus posibilidades de movilidad. Desde esta perspectiva el análisis de la mujer migrante y de su inclusión en los mercados de trabajo no es separable de la institución familiar y de consideraciones sobre la existencia de un conjunto de dispositivos culturales orientados a la reproducción de los roles tradicionales asociados a ella (Laphere 1986).

Para abordar esta dimensión sociocultural se ha procedido a utilizar la información recopilada en los prontuarios de extranjería, sumados a la información de matrimonios disponibles en los archivos del registro civil. A partir de estos elementos es posible caracterizar ciertos aspectos específicos de la vida de las mujeres extranjeras en la 
ciudad, generando un conjunto de indicadores que dan cuenta de su inserción en la vida socioeconómica de la comunidad. A pesar de la limitación de los datos se han considerado cuatro aspectos relevantes para el análisis. En primer lugar A) los patrones de nupcialidad y los niveles de endogamia existentes en las comunidades de migrantes en la comunidad que los acoge, esto por cuanto el proyecto familiar en dicho período se constituye a partir de la institución matrimonial, y donde la endogamia señalaría un rasgo asociado no solo al tamaño de las comunidades migrantes, lo que genera más oportunidades de calce matrimonial para connacionales, sino también a la capacidad de generar condiciones más elevadas de reproducción cultural para la comunidad migrante. En segundo lugar B) caracterizar la diversidad/concentración de los orígenes geográficos de los migrantes, por cuanto se plantea que mayor diversidad de los lugares desde donde ellos/as provienen reduce los niveles de endogamia y aumenta las oportunidades de innovación cultural, al mismo tiempo la migración asociada a efectos de redes sociales serían más probables en contextos de origen geográfico más concentrado (MacDonald y MacDonald 1964). El tercer aspecto sería C) la forma de inserción en el mercado laboral, en este caso particular esto se verifica en la caracterización de los patrones ocupacionales de los/las migrantes. Según LaFortune y Tessada (2012), el estudio de la diversidad de estos patrones es reflejo del volumen y antigüedad de los flujos migratorios y de la forma en que las redes sociales de los migrantes van creando oportunidades laborales. Además, siguiendo a Pinto (1990) en este período histórico también es relevante la constitución de categorías sociales asociadas a la proletarización del trabajo.

Un punto relevante de notar, tanto para el caso de la diversidad en los lugares de partida de los migrantes, así como en la variedad de las ocupaciones que desarrollan en los lugares en los que se instalan, puede ser medida a través de un índice de diversidad y/o su opuesto mediante un índice de concentración. Por efectos de su sencillez de cálculo en el trabajo se ha utilizado el llamado indicador de concentración de Hirschman-Herfindahl. ${ }^{8}$

8 El indicador de Herfindahl-Hirschman (HHI) que se define como: $\mathrm{HHI}=\sum_{i=1}^{n}(p i / P T)^{2}$

Donde pi es el número de personas inmigrantes de nacionalidad "h" originarias de la localización "i" y PT es el número total de personas migrantes de nacionalidad " $h$ ". Si el valor HHI tiende a
Finalmente un cuarto aspecto tiene relación con D) la participación de la familia en el proceso migratorio, lo que implica distinguir los tipos de proyectos migratorios en términos de si son individuos o familias los que migran. Cabe hacer notar que para efectos de consistencia en la presentación de los datos, los indicadores agregados se han incluido utilizando como cortes relevantes los mismos períodos censales previamente utilizados.

\section{A. Nupcialidad y endogamia de las comunidades migrantes}

Siguiendo a Sánchez-Domínguez (2011), la endogamia matrimonial puede ser vista como un indicador del grado de integración de los inmigrantes a su sociedad receptora, en la medida que los matrimonios mixtos (no endogámicos) son una estrategia de integración que permite a los inmigrantes "enraizarse" en la sociedad receptora mediante vínculos permanentes y alto compromiso simbólico. En oposición a la idea anterior, la endogamia matrimonial ha sido percibida como una estrategia defensiva que limita la integración social multiétnica y que preserva las diferencias al interior de la sociedad receptora. Esto podría deberse a que el grupo inmigrante encuentra resistencias y es afectado por prácticas de segregación/discriminación y/o porque el mismo grupo inmigrante opta por una estrategia separada, en la que los vínculos permanentes de gran valor simbólico se reservan para sus propios conciudadanos.

Al respecto, se ha destacado que los inmigrantes, en las primeras etapas de su asentamiento, tienden a mantener patrones de endogamia matrimonial elevados, como consecuencia de la estrechez de la red social en la que se insertan. De esta manera, la endogamia correspondería a una estrategia de reducción de la incertidumbre producida por el nuevo entorno social y también como una forma de conservación de la propia

\footnotetext{
o significa que la distribución de orígenes es poco concentrada o muy diversa (Rhoades 1993). En oposición, si HHI tiende a 1 significa que no hay diversidad, que la variable está completamente concentrado, es decir, que todos los migrantes provienen de la misma localidad en el país de origen. La misma idea se aplica a las ocupaciones, HHI bajo indicaría mucha diversidad en tipos ocupacionales, mientras que un HHI más alto, en el extremo =1 significa que todos los migrantes tienen la misma ocupación (concentración total).
} 
cultura, sobre todo cuando se trata de proyectos migratorios que incluyen la posibilidad de retorno en el corto o mediano plazo (Blau, Blum y Schwartz 1982). Para controlar entonces por efecto del tamaño de la comunidad inmigrante, puesto que sus oportunidades de emparejamiento se reducen conforme ésta es pequeña y/o altamente masculinizada, se considera pertinente controlar por el número de mujeres presentes en la comunidad, por lo que un indicador refinado de endogamia se puede deducir a partir de la situación particular de las mujeres ${ }^{9}$ (Lievens 1998).

En el caso en estudio, se examinaron los patrones de nupcialidad, utilizando la información de matrimonios del Registro Civil y de Identificación para los libros desde 1885 a 1930. Esta información se sintetiza según la nacionalidad del contrayente. Para estos efectos se entiende un matrimonio endogámico cuando ambos contrayentes son de la misma nacionalidad, y se define como exogámico cuando son de nacionalidades diferentes. En la Tabla 3 se presenta el número de personas casadas según esta categorización y agregadas por período censal, separando a los contrayentes según su sexo. En los casos exogámicos, los números de casados por sexos son asimétricos puesto que las personas se han casado con otras de diferente nacionalidad. Claramente la cantidad de casados/as es una función del tamaño respectivo de la población subyacente, por lo

9 Para estos efectos se proponen dos indicadores operativos ante un contexto altamente masculinizado como el que se examina.

Índice de Endogamia Bruta= Número de Hombre y Mujeres casados con personas de su misma nacionalidad "k" en período de tiempo " $\mathrm{t}$ "/Total de personas hombres y mujeres de nacionalidad " $k$ " que contraen matrimonio en período de tiempo " $\mathrm{t}$ ", con independencia de nacionalidad de co-contrayente. Índice de Endogamia Neta= Número de Mujeres casadas con personas de su misma nacionalidad " $k$ " en período de tiempo "t"/Total de Mujeres de nacionalidad " $k$ " que contraen matrimonio en período de tiempo " $\mathrm{t}$ ", con independencia de nacionalidad del marido.

El primer indicador señala la probabilidad de un matrimonio en endogamia dado el universo total de matrimonios acaecidos en un período establecido para un grupo nacional. Mientras que el segundo señala la probabilidad de un matrimonio en endogamia dado el total de matrimonios acaecidos considerando una población restringida por la menor presencia relativa de mujeres en cada grupo nacional. que se introducen los indicadores de endogamia bruta y neta ya descritos.

En la Tabla 4 se presentan los resultados de los indicadores de endogamia, los valores brutos indican que las comunidades boliviana y peruana son relativamente más cerradas que la argentina, es decir, que es más probable que tanto hombres como mujeres de esos grupos tengan un matrimonio con un connacional que con una persona de otra nacionalidad. En términos de la secuencia histórica, los indicadores crecen conforme crece el tamaño de la comunidad inmigrante, lo que es consistente con la literatura sobre este punto; esto además implica que las mayores oportunidades de selección de parejas reducen la mixtura cultural para el caso boliviano.

Los resultados para los índices netos es similar, nuevamente la comunidad boliviana y peruana aparecen como extremadamente más endogámicas, en ese orden, y con baja prevalencia en el caso de la comunidad argentina. En los casos boliviano y peruano los resultados indican que cuando se trata de mujeres es mucho más probable que la pareja salga de la misma comunidad nacional, reduciendo la mixtura étnica, lo que es completamente compatible con la asimetría absoluta en cantidades de hombres y de mujeres en las respectivas comunidades migrantes, hecho que ha sido destacado mediante indicación de los altos índices de masculinidad presentes en estos casos.

\section{B. Diversidad /Concentración Geográfica de las migrantes}

La experiencia migratoria de las mujeres se considera muy afectada por sus condiciones sociales y personales al momento de su partida, también esto se ve mediado por el propósito de su proyecto migratorio. De esta manera la comunidad de origen, como una localización geográfica específica, ayuda a comprender por qué algunas mujeres migran, en la medida que permite definir un marco sociocultural en el cual se insertan y desenvuelven. Varios elementos están incluidos en este marco: la estructura familiar y la distribución sexual de roles en las sociedades originarias, así como las posibilidades de desarrollar una vida en la nueva comunidad de acogida que sea compatible con el marco preexistente, incluidos sus mecanismos de control social y de subordinación que afecta a las mujeres. En este contexto la presencia de grupos migrantes 


\begin{tabular}{|c|c|c|c|c|c|}
\hline Período & Sexo & Nacionalidad & Argentinos(as) & Bolivianos(as) & Peruanos(as) \\
\hline \multirow{4}{*}{ De 1880 a 1895} & \multirow{2}{*}{ Hombres } & $\begin{array}{l}\text { Matrimonios } \\
\text { Exogámicos }\end{array}$ & 17 & 27 & 7 \\
\hline & & $\begin{array}{l}\text { Matrimonios } \\
\text { Endogámicos }\end{array}$ & 2 & 4 & 2 \\
\hline & \multirow{2}{*}{ Mujeres } & $\begin{array}{l}\text { Matrimonios } \\
\text { Exogámicos }\end{array}$ & 15 & 30 & 26 \\
\hline & & $\begin{array}{l}\text { Matrimonios } \\
\text { Endogámicos }\end{array}$ & 2 & 4 & 2 \\
\hline \multirow{4}{*}{ De 1896 a 1907} & \multirow{2}{*}{ Hombres } & $\begin{array}{l}\text { Matrimonios } \\
\text { Exogámicos }\end{array}$ & 32 & 45 & 52 \\
\hline & & $\begin{array}{l}\text { Matrimonios } \\
\text { Endogámicos }\end{array}$ & 0 & 62 & 24 \\
\hline & \multirow{2}{*}{ Mujeres } & $\begin{array}{l}\text { Matrimonios } \\
\text { Exogámicos }\end{array}$ & 18 & 30 & 42 \\
\hline & & $\begin{array}{l}\text { Matrimonios } \\
\text { Endogámicos }\end{array}$ & o & 62 & 24 \\
\hline \multirow{4}{*}{ De 1908 a 1920} & \multirow{2}{*}{ Hombres } & $\begin{array}{l}\text { Matrimonios } \\
\text { Exogámicos }\end{array}$ & 43 & 66 & 86 \\
\hline & & $\begin{array}{l}\text { Matrimonios } \\
\text { Endogámicos }\end{array}$ & 2 & 112 & 20 \\
\hline & \multirow{2}{*}{ Mujeres } & $\begin{array}{l}\text { Matrimonios } \\
\text { Exogámicos }\end{array}$ & 25 & 46 & 44 \\
\hline & & $\begin{array}{l}\text { Matrimonios } \\
\text { Endogámicos }\end{array}$ & 2 & 112 & 20 \\
\hline \multirow{4}{*}{ De 1921 a 1930} & \multirow{2}{*}{ Hombres } & $\begin{array}{l}\text { Matrimonios } \\
\text { Exogámicos }\end{array}$ & 19 & 34 & 4 \\
\hline & & $\begin{array}{l}\text { Matrimonios } \\
\text { Endogámicos }\end{array}$ & 2 & 46 & o \\
\hline & \multirow{2}{*}{ Mujeres } & $\begin{array}{l}\text { Matrimonios } \\
\text { Exogámicos }\end{array}$ & 26 & 40 & 10 \\
\hline & & $\begin{array}{l}\text { Matrimonios } \\
\text { Endogámicos }\end{array}$ & 2 & 46 & 0 \\
\hline
\end{tabular}

Fuente: Elaboración propia con base a libro de matrimonios del Registro Civily de Identificación de la Provincia de Antofagasta, años 1880 al 1930.

Tabla 3. Personas que contraen matrimonio según períodos de análisis. 


\begin{tabular}{|c|c|c|c|c|c|}
\hline & \multicolumn{2}{|c|}{ Argentinos(as) } & \multicolumn{2}{c|}{ Bolivianos(as) } & \multicolumn{1}{c|}{ Peruanos(as) } \\
\hline Período en análisis & $\begin{array}{c}\text { Índice de } \\
\text { Endogamia Bruta }\end{array}$ & $\begin{array}{c}\text { Índice de } \\
\text { Endogamia Neta } \\
\text { Endogamia Bruta }\end{array}$ & $\begin{array}{c}\text { Índice de } \\
\text { Endogamia Neta }\end{array}$ & $\begin{array}{c}\text { Índice de } \\
\text { Endogamia Bruta } \\
\text { Endogamia Neta }\end{array}$ \\
\hline De 1880 a 1895 & 0,11 & 0,12 & 0,12 & 0,12 & 0,67 \\
\hline De 1896 a 1907 & 0 & 0 & 0,62 & 0,11 \\
\hline De 1908 a 1920 & 0,06 & 0,07 & 0,67 & 0,71 & 0,34 \\
\hline De 1921 a 1930 & 0,08 & 0,07 & 0,55 & 0,53 & 0 \\
\hline
\end{tabular}

Fuente: Elaboración propia con base a libro de matrimonios del Registro Civil y de Identificación de la Provincia de Antofagasta, años 1880 al 1930.

Tabla 4. Índices de Endogamia Bruta y Neta para departamento de Antofagasta.

numerosos, y con un origen geográfico común y concentrado, generaría condiciones ideales para la reproducción de las pautas culturales de la comunidad originaria. Este escenario determinaría condiciones que facilitan la endogamia matrimonial; además este mecanismo puede generar nuevos flujos migratorios en la medida que las "novias prometidas" aún residan en el país de origen. Este tipo de prácticas aumenta la cohesión social de los grupos migrantes ya instalados y facilitan la llegada de los nuevos/as migrantes reduciendo los costos de migración y de localización (MacDonald y MacDonald 1964)

Para el estudio de las comunidades de origen en este caso se utiliza la información declarada en los prontuarios respectivos, en todos ellos el registro de entrada al país corresponde al período entre los años 1880 y 1930 inclusive. Para el caso de los ciudadanos argentinos se han examinado 756 hombres y 80 mujeres. Para el caso boliviano, 3.420 hombres y 550 mujeres, y finalmente para el peruano, 107 hombres y 44 mujeres.

Esta información contenida en los prontuarios se genera de la propia declaración de la persona migrante, por lo que en ella no hay consistencia sobre la unidad geográfica de referencia al identificar su origen. En algunos casos la localización de origen se expresa como regiones o provincias, en otros mediante referencias más específicas como ciudades y pueblos. Para efectos prácticos en este reporte cada loca- lización declarada se ha considerado comparable, aunque opere a diferente escala geográfica en el país de origen..$^{10}$

Lo importante es que ellas reflejan la referencia de localización relevante para la persona migrante, por lo que la convergencia hacia los mismos orígenes -lo que es equivalente a concentración en las comunidades de origen- solo revela la existencia de una comunidad originaria amplia, compatible con las hipótesis de migraciones en red y facilitadoras de la preservación de los marcos socioculturales originarios. Los resultados sobre las localidades desde las que partieron las/os inmigrantes se presentan en la Tabla 5 .

Los resultados de los índices de concentración calculados, indican que para el caso argentino los patrones son concentrados tanto para mujeres como hombres. El índice HHI para mujeres alcanza un valor de 0.167 , mientras que para los hombres es de 0.147 , ambos grupos provenientes mayoritariamente de las provincias de Catamarca ( $28 \%$ de los hombres y $24 \%$ de las mujeres), Buenos

10 Los flujos migratorios desde las localidades de origen, están también determinados por la distribución espacial de la población en los países originarios. Se esperaría que áreas con mayores volúmenes de población generaran mayor número de migrantes. En el caso latinoamericano, la distribución espacial de la población a finales del siglo XIX y principios del XX se reconoce como concentrada en torno a un conjunto reducido de ciudades primadas, cuyo eje principal es generalmente la capital nacional (Cuervo 2004). Esto también fue previamente examinado por Sánchez (1974) en el capítulo 7 de su trabajo de tesis. 


\begin{tabular}{|l|r|r|r|r|}
\hline \multicolumn{2}{|c|}{ Caso Argentinos (as). } & \multicolumn{2}{c|}{} \\
\cline { 1 - 2 } & \multicolumn{2}{|c|}{ Hombres } & \multicolumn{2}{c|}{ Mujeres } \\
\hline Localidad & casos & \multicolumn{1}{c|}{$\%$} & casos & $\%$ \\
\hline Catamarca & 212 & $28 \%$ & 19 & $24 \%$ \\
\hline Buenos Aires & 121 & $16 \%$ & 22 & $27 \%$ \\
\hline Salta & 106 & $14 \%$ & 6 & $8 \%$ \\
\hline La Rioja & 83 & $11 \%$ & 4 & $5 \%$ \\
\hline Mendoza & 53 & $7 \%$ & 7 & $9 \%$ \\
\hline San Juan & 45 & $6 \%$ & 6 & $8 \%$ \\
\hline Jujuy & 38 & $5 \%$ & 0 & $0 \%$ \\
\hline Tucumán & 23 & $3 \%$ & 7 & $9 \%$ \\
\hline Santa Fe & 30 & $4 \%$ & 5 & $6 \%$ \\
\hline Córdoba & 15 & $2 \%$ & 2 & $3 \%$ \\
\hline Total & $\mathbf{7 2 6}$ & $96 \%$ & 79 & $99 \%$ \\
\hline
\end{tabular}

Fuente: Elaboración propia con base a los prontuarios migratorios. Archivo Histórico Universidad Católica del Norte: Cajas de Prontuarios de Extranjería correspondientes a Argentina (Cajas 1-7)

\begin{tabular}{|l|r|r|r|r|}
\hline \multicolumn{3}{|c|}{ Caso Bolivianos (as) } & \multicolumn{2}{c|}{} \\
\cline { 1 - 2 } & \multicolumn{2}{|c|}{ Hombres } & \multicolumn{2}{c|}{ Mujeres } \\
\hline Localidad & casos & \multicolumn{1}{c|}{$\%$} & casos & \multicolumn{1}{c}{$\%$} \\
\hline Cochabamba & 1265 & $37 \%$ & 132 & $24 \%$ \\
\hline Potosí & 342 & $10 \%$ & 248 & $45 \%$ \\
\hline Oruro & 308 & $9 \%$ & 28 & $5 \%$ \\
\hline La Paz & 274 & $8 \%$ & 50 & $9 \%$ \\
\hline Sucre & 171 & $5 \%$ & 39 & $7 \%$ \\
\hline Quillacollo & 171 & $5 \%$ & 6 & $1 \%$ \\
\hline Tupiza & 68 & $2 \%$ & 6 & $1 \%$ \\
\hline Uyuni & 68 & $2 \%$ & 6 & $1 \%$ \\
\hline Total & $\mathbf{2 6 6 8}$ & $\mathbf{7 8} \%$ & $\mathbf{5 1 2}$ & $\mathbf{9 3} \%$ \\
\hline
\end{tabular}

Fuente: Elaboración propia con base a los prontuarios migratorios. Archivo Histórico Universidad Católica del Norte: Cajas de Prontuarios de Extranjería correspondientes a Bolivia (Cajas $42-78)$

\begin{tabular}{|l|c|c|c|c|}
\hline \multicolumn{3}{|c|}{ Caso Peruanos (as). } & \multicolumn{2}{|c|}{} \\
\hline & \multicolumn{2}{|c|}{ Hombres } & \multicolumn{2}{c|}{ Mujeres } \\
\hline Localidad & casos & $\%$ & casos & $\%$ \\
\hline Lima & 35 & $33 \%$ & 19 & $44 \%$ \\
\hline Arequipa & 19 & $18 \%$ & 7 & $16 \%$ \\
\hline Callao & 9 & $8 \%$ & 5 & $12 \%$ \\
\hline Mollendo & 5 & $5 \%$ & 4 & $8 \%$ \\
\hline Tacna & 5 & $5 \%$ & 2 & $4 \%$ \\
\hline Ica & 5 & $5 \%$ & 0 & $0 \%$ \\
\hline Huánuco & 2 & $2 \%$ & 2 & $4 \%$ \\
\hline Piura & 3 & $3 \%$ & 0 & $0 \%$ \\
\hline Ancash & 2 & $2 \%$ & 0 & $0 \%$ \\
\hline Ayacucho & 2 & $2 \%$ & 0 & $0 \%$ \\
\hline Total & 89 & $83 \%$ & 39 & $88 \%$ \\
\hline
\end{tabular}

Fuente: Elaboración propia con base a los prontuarios migratorios. Archivo Histórico Universidad Católica del Norte: Cajas de Prontuarios de Extranjería correspondientes a Perú (Cajas 168-172)

Tabla 5. Lugares de origen para los tres grupos inmigrantes

a. Caso Argentinos/as b. Caso Bolivianos/as c. Caso Peruanos/as

Aires ( $16 \%$ y $27 \%$ respectivamente), Salta $(14 \%$ y $8 \%)$ y La Rioja (11\% y 5\%).

Para el caso boliviano, los patrones son los más concentrados comparados con los otros dos grupos en estudio, los índices HHI son 0.172 para hombres y 0.279 para mujeres. Los hombres mayoritariamente provienen de Cochabamba, Potosí y Oruro con aportes relativos de $37 \%, 10 \%$ y $9 \%$ respectivamente. Para las mujeres el orden de contribución sufre cambios; ellas provienen mayoritariamente de Potosí, Cochabamba y de La Paz, con magnitudes de $45 \%$, 24\% y $9 \%$ respectivamente.

Para el caso peruano la concentración está en una posición intermedia, es mayor comparada con la argentina, pero menor que la boliviana. Es este caso nuevamente las mujeres presentan mayor concentración en términos de localidades de origen, mujeres $\mathrm{HHI}=0.246$ versus hombres $\mathrm{HHI}=0.158$. La comunidad inmigrante proviene mayoritariamente de Lima (33\% para los hombres y $44 \%$ para mujeres), de Arequipa (18\% y $16 \%$ respectivamente) y El Callao (8\% y $12 \%)$.

Los resultados combinados para los tres grupos nacionales se organizan en forma descrita en la Figura 1.
Estos resultados indican que las mujeres sistemáticamente tienen menos diversidad que los hombres, lo que supone que en el caso de ellas es más probable que operen con intensidad mecanismos de migración en redes a través de familiares y conocidos, y que por lo tanto se generen condiciones de mayor reproductividad de su cultura original, incluyendo todos los dispositivos de control social inherentes.

Cuando se comparan las nacionalidades entre ellas, en términos relativos, la situación de las argentinas es más diversa, y desde esta perspectiva mejor que la situación de peruanas y de bolivianas, quienes tendrían la posición de mayor debilidad relativa.

Como se señalaba anteriormente, la comunidad boliviana, por tener un volumen migratorio mayor (es 4.7 veces la de Argentina y 26 veces la de Perú), ofrece la posibilidad de que se configure un espacio social en la comunidad receptora de Antofagasta que facilite las condiciones de reproducción de la cultura de origen en el nuevo escenario, lo que en el contexto de existencia de culturas patriarcales dominantes en las localidades originarias significa ambientes de mayor control social hacia la mujer. 


\section{Patrones de ocupación de las migrantes}

Siguiendo a Courtis y Pacecca (2010), en la teoría migratoria tradicional se ha tendido a ignorar las especificidades de la migración femenina, en su doble dimensión de la decisión de migrar, así como del proceso migratorio en sí mismo, además de las formas de inserción en la sociedad de destino. A diferencia de la migración masculina, los grados de autonomía asociados a la migración femenina son menores, puesto que las mujeres se sitúan en entramados de relaciones contextuales complejas. Esto ha dado lugar al estudio de los patrones migratorios femeninos en el contexto de redes familiares distribuidas que siguen un patrón asociativo, ligadas a familiares (padres, esposos y hermanos/as). Esta complejidad también afecta las oportunidades de inserción en la comunidad receptora, particularmente las laborales. Se reconoce que los espacios ocupacionales son limitados y que en muchos casos solo se producen en ocupaciones que se consideran una proyección de los roles reproductivos al espacio de los servicios, por ejemplo en educación (profesoras, institutrices), salud (enfermeras, cuidadoras), servicio doméstico (cocineras, lavanderas, costureras), etcétera.

En oposición a lo anterior, igualmente se ha señalado que en este contexto las mujeres también pueden tener una participación en empleos de baja productividad, muy precarios, caracterizados en inglés como del tipo 3D por "Dangerous, Dirty and Demeaning" (Piore 1979), los que corresponderían a ocupaciones como lavanderas, servicio doméstico, vendedoras ambulantes, etcétera.

Para efectos de la caracterización sobre qué tan diversas o concentradas son las oportunidades ocupacionales para las mujeres migrantes, nuevamente se utiliza la información declarada en los prontuarios respectivos y los índices HHI, pero esta vez calculados para proporciones de ocupados/as en las diferentes categorías que se reportan en los prontuarios.

En la Tabla 6 se resumen las ocupaciones con mayor frecuencia relativa declaradas. Los resultados de la estructura de ocupaciones muestran que éstas tienden a concentrarse en algunas pocas actividades. No obstante esta característica general, los resultados son diferentes por país.

En el caso de la población argentina, los varones tienen una mayor participación en las actividades de jornaleros (25\%), comerciantes (12\%), agricultores (11\%) y empleados (10\%). Las argentinas, en cambio, se concentran en posiciones tradicionales como las labores del hogar (56\%) y en oficios precarios, como lavanderas, cocineras y modistas/costureras (16\%). En esta sección llama la atención un grupo de artistas (9\%) y de prostitutas (4\%). Cuando esta distribución ocupacional se representa como un indicador de concentración ocupacional, los hombres argentinos aparecen menos concentrados $(\mathrm{HHI}=0.105)$ que las mujeres $(\mathrm{HHI}=0.338)$; esto implica que las oportunidades de inserción en diferentes tipos de ocupaciones para ellos son más diversas que las disponibles para las mujeres.

En términos de las ocupaciones para el caso boliviano, ellos aparecen concentrados en posiciones como jornaleros (30\%), agricultores (7\%) y en un grupo de oficios calificados más urbanos como sastres, empleados, mecánicos y comerciantes (24\%). Las migrantes bolivianas, en cambio, presentan resultados concentrados en las labores del hogar (o del sexo, como aparecen oficialmente

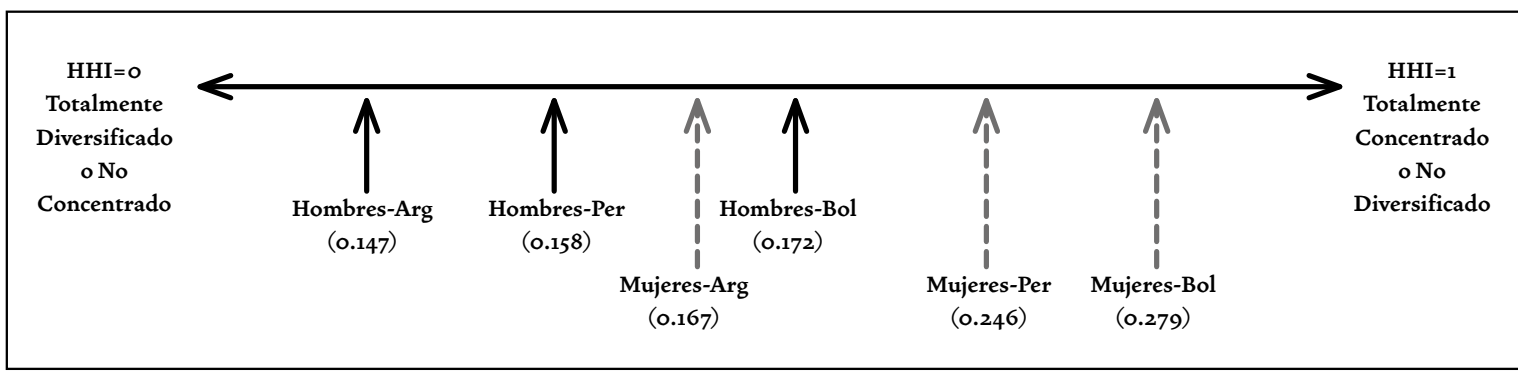

Fuente: Elaboración propia sobre la base de prontuarios.

Figura 1. Resumen Índices de Concentración según localidades de origen de los inmigrantes. 
registradas), con un 39\% (ésta es la proporción más baja en los tres grupos nacionales examinados), comerciantes (10\%), modistas/costureras ( $8 \%$ ) y jornaleras (5\%).

Nuevamente cuando se convierte la distribución ocupacional en un índice de concentración tipo HHI, la situación de la inmigración boliviana muestra que los hombres tienen una concentración ocupacional $(\mathrm{HHI}=0.115)$ alta comparada con los hombres argentinos y peruanos. En oposición, para las mujeres bolivianas su índice $\mathrm{HHI}=0.174$ es mayor que el de sus compatriotas varones, pero es el menor en comparación con las mujeres de Argentina o Perú.
Para el caso de la inmigración peruana, ellos aparecen participando en posiciones de empleados (25\%), comerciantes $(8 \%)$ y cocineros (7\%). En contraste, las inmigrantes peruanas se concentran en ocupaciones tradicionales como las labores de casa (48\%), comerciantes $(8 \%)$ y modistas/costureras (8\%). Cuando la distribución ocupacional se reduce al indicador de concentración $\mathrm{HHI}$, los resultados nuevamente muestran una situación más diversa para ellos $(\mathrm{HHI}=0.088)$ y más concentrada para ellas $(\mathrm{HHI}=0.264)$. Estos valores implican que en los inmigrantes peruanos subsisten diferencias entre hombres y mujeres, que para el caso

\begin{tabular}{|c|c|c|c|c|}
\hline \multicolumn{2}{|c|}{ CasoArgentinos (as). } & & & \\
\hline \multirow[b]{2}{*}{ Actividad } & \multicolumn{2}{|c|}{ Hombres } & \multicolumn{2}{|c|}{ Mujeres } \\
\hline & casos & $\%$ & casos & $\%$ \\
\hline Jornalero & 189 & $25 \%$ & o & ०\% \\
\hline Comerciante & 91 & $12 \%$ & 4 & $5 \%$ \\
\hline Agricultor & 83 & $11 \%$ & o & $0 \%$ \\
\hline Empleado & 76 & $10 \%$ & 2 & $3 \%$ \\
\hline Mecánico & 45 & $6 \%$ & o & $0 \%$ \\
\hline Minero & 38 & $5 \%$ & o & ०\% \\
\hline Artista & 15 & $2 \%$ & 7 & $9 \%$ \\
\hline Carpintero & 15 & $2 \%$ & o & ०\% \\
\hline Fogonero & 8 & $1 \%$ & o & $0 \%$ \\
\hline $\begin{array}{l}\text { Chofer/ } \\
\text { conductores }\end{array}$ & 8 & $1 \%$ & o & $0 \%$ \\
\hline $\begin{array}{l}\text { Labores del } \\
\text { Sexo }\end{array}$ & o & ०\% & 45 & $56 \%$ \\
\hline Lavandera & o & ०\% & 4 & $5 \%$ \\
\hline Cocinero & 8 & $1 \%$ & 3 & $4 \%$ \\
\hline Modista & ० & $0 \%$ & 3 & $4 \%$ \\
\hline Prostituta & o & ०\% & 3 & $4 \%$ \\
\hline Empleado & 76 & $10 \%$ & 2 & $3 \%$ \\
\hline Costurera & o & ०\% & 2 & $3 \%$ \\
\hline Total & 650 & $86 \%$ & 77 & $96 \%$ \\
\hline
\end{tabular}

\begin{tabular}{|c|c|c|c|c|}
\hline \multicolumn{2}{|c|}{ Caso Bolivianos (as). } & & & \\
\hline \multirow[b]{2}{*}{ Actividad } & \multicolumn{2}{|c|}{ Hombres } & \multicolumn{2}{|c|}{ Mujeres } \\
\hline & casos & $\%$ & casos & $\%$ \\
\hline Jornalero & 1026 & $30 \%$ & 28 & $5 \%$ \\
\hline Sastre & 274 & $8 \%$ & 6 & $1 \%$ \\
\hline Agricultor & 239 & $7 \%$ & o & ०\% \\
\hline Empleado & 205 & $6 \%$ & 39 & $7 \%$ \\
\hline Mecánico & 205 & $6 \%$ & o & ०\% \\
\hline Comerciante & 137 & $4 \%$ & 55 & $10 \%$ \\
\hline Carpintero & 137 & $4 \%$ & o & ०\% \\
\hline Minero & 103 & $3 \%$ & o & ०\% \\
\hline Estudiante & 103 & $3 \%$ & 17 & $3 \%$ \\
\hline Contador & 68 & $2 \%$ & o & ०\% \\
\hline $\begin{array}{l}\text { Labores del } \\
\text { Sexo }\end{array}$ & o & ०\% & 215 & $39 \%$ \\
\hline $\begin{array}{l}\text { Modista/ } \\
\text { Costurera }\end{array}$ & o & $0 \%$ & 44 & $8 \%$ \\
\hline Total & 2497 & $73 \%$ & 402 & $80 \%$ \\
\hline
\end{tabular}

Fuente: Elaboración propia con base a los prontuarios migratorios. Archivo Histórico Universidad Católica del Norte: Cajas de Prontuarios de Extranjería correspondientes a Bolivia (Cajas 42-78)

\begin{tabular}{|c|c|c|c|c|}
\hline \multirow[b]{2}{*}{ Actividad } & \multicolumn{2}{|c|}{ Hombres } & \multicolumn{2}{|c|}{ Mujeres } \\
\hline & casos & $\%$ & casos & $\%$ \\
\hline Empleado & 26 & $25 \%$ & 2 & $4 \%$ \\
\hline Comerciante & 9 & $8 \%$ & 4 & $8 \%$ \\
\hline Cocinero & 7 & $7 \%$ & o & ०\% \\
\hline Artista & 5 & $5 \%$ & 2 & $4 \%$ \\
\hline Mecánico & 5 & $5 \%$ & o & ०\% \\
\hline Abogado & 4 & $3 \%$ & 0 & ०\% \\
\hline Fogonero & 4 & $3 \%$ & o & ०\% \\
\hline Jornalero & 4 & $3 \%$ & o & ०\% \\
\hline Maquinista & 4 & $3 \%$ & o & ०\% \\
\hline Peluquero & 4 & $3 \%$ & o & ०\% \\
\hline Sastre & 4 & $3 \%$ & o & ०\% \\
\hline $\begin{array}{l}\text { Labores del } \\
\text { sexo }\end{array}$ & o & $0 \%$ & 21 & $48 \%$ \\
\hline $\begin{array}{l}\text { Modista/ } \\
\text { Costurera }\end{array}$ & o & $0 \%$ & 4 & $8 \%$ \\
\hline Enfermera & o & ०\% & 2 & $4 \%$ \\
\hline Lavandera & o & ०\% & 2 & $4 \%$ \\
\hline Total & 74 & $70 \%$ & 35 & $80 \%$ \\
\hline
\end{tabular}

Fuente: Elaboración propia con base a los prontuarios migratorios. Archivo Histórico Universidad Católica del Norte: Cajas de Prontuarios de Extranjería correspondientes a Perú (Cajas 168-172)

Fuente: Elaboración propia con base a los prontuarios migratorios. Archivo Histórico Universidad Católica del Norte: Cajas de Prontuarios de Extranjería correspondientes a Argentina (Cajas 1-7)

Tabla 6. Importancia relativa de las ocupaciones para los tres grupos inmigrantes (como \% del total de casos) a. Caso Argentinos/as b. Caso Bolivianos/as c. Caso Peruanos/as 
de los patrones ocupacionales señalan que ellas tienen oportunidades ocupacionales tres veces menos diversas que ellos. Estos resultados, en todo caso, las ubican en una situación intermedia entre las mujeres bolivianas y las argentinas.

Otra vez, los resultados combinados para los tres grupos nacionales se organizan en la forma descrita en la Figura 2.

La Figura 2 permite observar la división sexual entre hombres y mujeres en términos de índices de concentración ocupacional para las tres nacionalidades. Sistemáticamente, las mujeres de cualquiera de las tres nacionalidades enfrentan oportunidades laborales menos diversificadas (más concentradas) que los hombres. Esto es particularmente agudo para el caso de las mujeres argentinas, quienes tienen una situación más concentrada (restringida) que es superior a tres veces la de los hombres de igual nacionalidad. En el caso de las mujeres peruanas, ellas enfrentan una situación también concentrada que es menor en comparación con las mujeres argentinas, pero que aun así excede tres veces el índice equivalente enfrentado por los hombres peruanos.

Finalmente, el caso boliviano representa la menor brecha relativa entre hombres y mujeres, puesto que el indicador de concentración de ellas solo excede 1:5 veces la situación de los hombres bolivianos.

Este efecto podría estar asociado al tamaño de la comunidad residente. El mayor número de varones permite la operación de redes de contacto que seguramente facilitan la obtención de un puesto de trabajo en áreas y tipos de labores en los cuales dicho grupo nacional ya se encuen- tra afianzado, de manera que la propia red de contactos laborales ayuda al cierre y a la concentración en unos pocos tipos de ocupaciones (efecto red laboral según LaFortune y Tessada 2012).

En contraste para las mujeres, cuando se pertenece a una comunidad inmigrante muy numerosa, el mayor número de connacionales, aunque ayude a la reproducción del ambiente social existente en el lugar de origen, facilita al mismo tiempo la generación de oportunidades laborales mayores que si se tratara de una comunidad de pequeño volumen. Este elemento es el que separa el caso de las mujeres bolivianas de la situación de las argentinas y peruanas. Así, el efecto del mayor tamaño de la comunidad residente ayudaría a crear oportunidades laborales que se traducen en mayor diversificación ocupacional, y de manera opuesta, aumentaría la concentración en los casos de grupos nacionales más pequeños. Otro efecto relevante que pudiese operar para el caso de las bolivianas, es que un mayor número de mujeres connacionales, sobre todo vinculadas por medio de lazos familiares y de amistad, crean oportunidades para que las labores domésticas y el cuidado de los hijos pueda ser distribuido entre varias mujeres cooperantes, con lo que se crean condiciones objetivas que facilitan la participación laboral de las mujeres, sobre todo en contextos en que las familias son vulnerables socioeconómicamente (Curran y Rivero-Fuentes 2003).

Finalmente, estos resultados son similares a los encontrados por Escobar (2013) en su estudio de las condiciones del mercado laboral de las provincias de Antofagasta y Tarapacá para el mismo período 1880 y 1930, pero centrado en la situación de las mujeres y

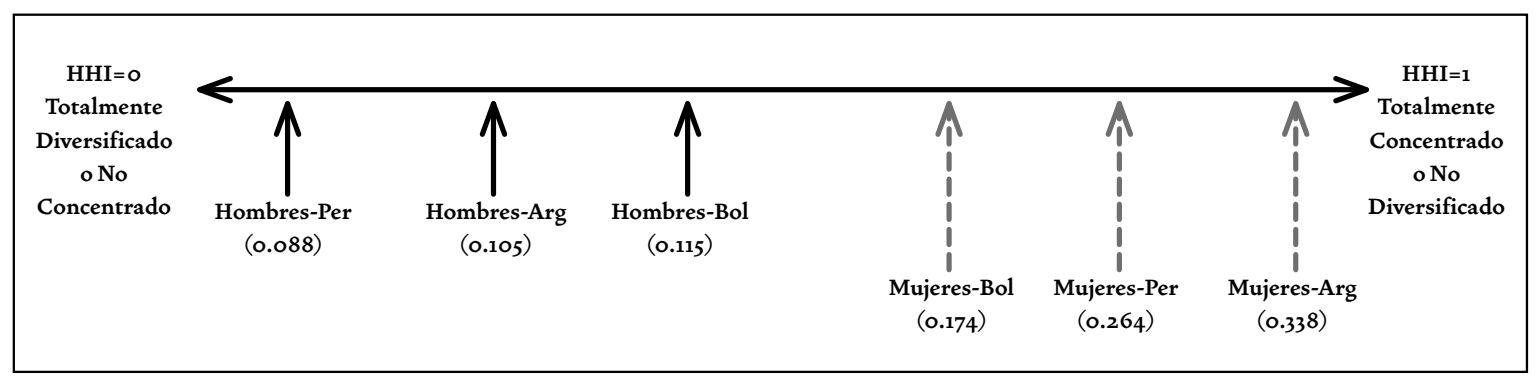

Fuente: Elaboración propia sobre la base de prontuarios.

Figura 2. Resumen Índices de Concentración según Ocupaciones de los Inmigrantes 
niñas chilenas. Su trabajo establece que respecto a la situación laboral de las mujeres, no se verifica una radical transformación en el sistema de ocupaciones femenino; ellas continúan participando en una forma intermedia entre lo tradicional y lo moderno, aun cuando efectivamente se verifica una situación de modernización económica en la provincia, asociada al sistema productivo propio de la minería del salitre.

\section{Estructuras familiares y formas migratorias}

Con relación a la estructura familiar, ya se ha establecido que es una variable relevante para comprender la situación contextual que determina la migración, sobre todo de la femenina (MacDonald y MacDonald 1964). En la llamada teoría de la nueva economía de la migración, se ha planteado también que las decisiones sobre la migración no las toman actores individuales de manera aislada, sino que en ellas participa gente relacionada, por ejemplo los hogares y familias de quienes migran. En estos espacios microsociales las personas no actúan como un individuo, sino que colectivamente para alcanzar sus fines, sean éstos maximizar los ingresos esperados, minimizar los riesgos y/o reducir las limitaciones impuestas por variadas dificultades asociadas al proceso migratorio. Desde esta perspectiva, existiría una forma migratoria asociada a un proyecto más bien individual y otro de tipo colectivo, donde la familia y las relaciones familiares juegan un rol central (Massey et al. 1993). Considerando estos elementos, se ha procedido a identificar grupos familiares migrantes con la información disponible en los prontuarios. Dada la limitación de la información, la forma de proceder consiste en identificar grupos de hermanos/as migrantes a partir del examen de varias condiciones lógicas que se reseñan: la coincidencia de apellidos paternos y maternos, la coincidencia de los nombres individuales de padre y madre y examinando la coincidencia en la dirección de residencia declarada en la ciudad.

Utilizando estos criterios, ha sido posible identificar un conjunto de familias constituidas por hermanos migrantes. Para el caso argentino se ha identificado a 19 familias que involucran un total de 43 hermanos/as $(5.1 \%$ de los argentinos), para el caso boliviano se han identificado 143 familias con un total de 256 personas $(6.8 \%$ de los bolivianos residentes), y para el caso peruano se identifican solo dos grupos familiares, con un total de cinco personas ( $3.3 \%$ de los peruanos). Los detalles de la distribución de las personas por grupo nacional se encuentran disponibles en Tabla 7.

Al considerar la distribución relativa de las personas entre aquellos que tienen un grupo de hermanos asociado y los que no, se puede estudiar la localización relativa de las personas en estas categorías y los coeficientes de localización asociados. Debe recordarse que desde una perspectiva de migración femenina, los contextos familiares facilitan la migración transnacional de la mujer y por lo tanto se esperaría una mayor localización de ellas en dichos esquemas familiares o formas migratorias colectivas.

En este contexto de migrantes y de sus proyectos migratorios colectivos, los coeficientes de localización muestran el exceso de probabilidad de encontrar a una persona, sea hombre o mujer, en un determinado tipo de proyecto migratorio (individual/colectivo). Nuevamente los valores mayores que 1 expresan una localización alta. Los valores de la Tabla 8 ponen de manifiesto que no es clara una mayor localización relativa de las mujeres en los proyectos migratorios colectivos, que involucran a la familia, bajo la forma de hermanos/as. En el caso de las argentinas, la probabilidad de encontrar una mujer en un proyecto migratorio con hermanos es menor en un $2.8 \%$ a la probabilidad de encontrar una mujer dada la población residente en la provincia. Para el caso de las bolivianas, esta probabilidad excede en un $2.9 \%$ la de encontrar una mujer en la comunidad residente en la provincia, y para las peruanas es de un $31 \%$. Sobre la base de estos resultados, la migración femenina de los casos mencionados no parece vinculada intensamente a proyectos familiares, lo que probablemente se explique por la cercanía geográfica de los lugares de origen que permiten mantener un esquema de familia transnacional, es decir, en parte distribuida en las localidades de origen y en las de destino, factor que facilitaría el desplazamiento de las mujeres.

11 A estos índices se les calcularon sus intervalos de confianza al $95 \%$, según el método propuesto por Moineddin, Beyene y Boyle (2003), no resultando estadísticamente distintos de 1.0, por lo que no se considera un patrón significativamente diferente para hombres y mujeres. 


\begin{tabular}{|c|c|c|c|c|}
\hline \multirow{4}{*}{ Origen } & Proyecto Migrat. & Hombres & Mujeres & Total \\
\hline \multirow{4}{*}{ Argentina } & Sin Hermanos(as) & 717 & 76 & 793 \\
\cline { 2 - 5 } & Con Hermanos(as) & 39 & 4 & 43 \\
\cline { 2 - 5 } & Total & 756 & 80 & $\mathbf{8 3 6}$ \\
\hline \multirow{4}{*}{ Bolivia } & Sin Hermanos(as) & 3178 & 331 & 3509 \\
\cline { 2 - 5 } & Con Hermanos(as) & 242 & 14 & 256 \\
\cline { 2 - 5 } & Total & 3420 & 345 & 3765 \\
\hline \multirow{4}{*}{ Perú } & Sin Hermanos(as) & 103 & 43 & 146 \\
\cline { 2 - 6 } & Con Hermanos(as) & 4 & 1 & $\mathbf{1 5 1}$ \\
\cline { 2 - 5 } & Total & $\mathbf{1 0 7}$ & $\mathbf{4 4}$ & 5 \\
\hline
\end{tabular}

Fuente: Elaboración propia con base a los prontuarios migratorios. Archivo Histórico Universidad Católica del Norte: Cajas de Prontuarios de Extranjería correspondientes a:Argentina (Cajas 1-7), Bolivia (Cajas 42-78) y Perú (Cajas 168-172).

Tabla 7. Distribución de las personas migrantes en tipos de proyectos migratorios.

\begin{tabular}{|c|c|c|c|c|}
\hline & Proyecto Migrat. & Hombres & Mujeres & Total \\
\hline \multirow{4}{*}{ Argentina } & Sin Hermanos(as) & 1,000 & 1,002 & 1,000 \\
\cline { 2 - 5 } & Con Hermanos(as) & 1,003 & 0,972 & 1,000 \\
\cline { 2 - 5 } & Total & $\mathbf{1 , 0 0 0}$ & $\mathbf{1 , 0 0 0}$ & $\mathbf{1 , 0 0 0}$ \\
\hline \multirow{4}{*}{ Bolivia } & Sin Hermanos(as) & 0,997 & 1,029 & 1,000 \\
\cline { 2 - 5 } & Con Hermanos(as) & 1,041 & 0,597 & 1,000 \\
\cline { 2 - 5 } & Total & $\mathbf{1 , 0 0 0}$ & $\mathbf{1 , 0 0 0}$ & $\mathbf{1 , 0 0 0}$ \\
\hline \multirow{3}{*}{ Perú } & Sin Hermanos(as) & 0,996 & 1,011 & 1,000 \\
\cline { 2 - 5 } & Con Hermanos(as) & 1,129 & $\mathbf{0 , 6 8 6}$ & 1,000 \\
\cline { 2 - 5 } & Total & $\mathbf{1 , 0 0 0}$ & $\mathbf{1 , 0 0 0}$ & $\mathbf{1 , 0 0 0}$ \\
\hline
\end{tabular}

Fuente: Elaboración propia con base a los prontuarios migratorios. Archivo Histórico Universidad Católica del Norte: Cajas de Prontuarios de Extranjería correspondientes a: Argentina (Cajas 1-7), Bolivia (Cajas 42-78) y Perú (Cajas 168-172).

Tabla 8. Coeficientes de localización de las personas migrantes por tipos de proyectos migratorios ${ }^{11}$

\section{* Resultados y comentarios finales}

El desarrollo de la industria minera en la provincia de Antofagasta durante el auge del ciclo salitrero, estuvo asociado a un proceso de crecimiento económico y demográfico superior a la media nacional de Chile para el período 1880-1930. Al mismo tiempo, este desarrollo se vinculó a un proceso de industrialización modernizadora, que cimentó las bases para la aparición de formas modernas de organización de la producción, de nuevas relaciones sociales y de un conjunto amplio de transformaciones socioculturales que darán forma al país en el siglo XX. La situación del trabajo femenino en América Latina, en el mismo marco temporal, es otro campo social alterado por los cambios suscitados por el proceso de industrialización modernizadora, que incluyó entre otros elementos cambios también en la preeminencia de sectores económicos primarios, flujos migratorios internos, desde el campo hacia la ciudad, flujos migratorios internacionales y la constitución de un sistema 
productivo urbano basado en talleres y fábricas que abrieron posibilidades de nuevos trabajos para las mujeres.

En el marco de este proceso, la provincia de Antofagasta recibió un fuerte influjo migratorio de procedencias diversas. Las mujeres fueron parte significativa de este contingente, con fuerte presencia de migrantes peruanas, bolivianas y argentinas. La presencia femenina extranjera en la región de Antofagasta, fue el resultado de un doble proceso de cambio espacial, desde la migración interna, del campo a la ciudad, a una migración transfronteriza, de un país a otro, derivado de varios factores.

La adecuada comprensión del proceso migratorio reseñado, demandaba reconocer también que la situación de la mujer, y por lo tanto sus decisiones, están contenidas en un sistema de relaciones sociales que condicionan su movilidad, y en consecuencia el análisis de la mujer migrante y de su inclusión en los mercados de trabajo no es separable de la institución familiar y de consideraciones sobre la existencia de un conjunto de dispositivos culturales orientados a la reproducción de los roles tradicionales asociados a ellas.

En términos operacionales y dada la limitación de los datos, se optó por incorporar cuatro aspectos relevantes. En primer lugar, los patrones de nupcialidad y los niveles de endogamia existentes en las comunidades de migrantes. Un segundo aspecto, la diversidad/concentración de los orígenes geográficos de los migrantes, por cuanto esto críticamente afecta la reproductividad de patrones culturales en el nuevo país de acogida. Una tercera cuestión, la inserción en el mercado laboral, bajo la forma de patrones ocupacionales de las migrantes y finalmente, la distinción entre proyectos migratorios individuales o familiares.

Como fuentes de datos se utilizaron los censos de población para realizar caracterizaciones territoriales a nivel provincial y departamental, los libros de matrimonios disponibles en el Registro Civil y la información recopilada en los Prontuarios de Extranjería. Desde esta última fuente se examinaron 756 hombres y 80 mujeres de nacionalidad argentina, 3.420 hombres y 550 mujeres de nacionalidad boliviana, y finalmente 107 hombres y 44 mujeres del Perú.
Los principales resultados particulares apuntan a los siguientes elementos para el caso boliviano: en términos de su localización provincial versus departamental, se muestra que para el período 1895-1920, ellos están profundamente ligados a la provincia de Antofagasta y que además durante el período la población boliviana tendió a concentrarse en el departamento de Antofagasta, lo que estaría indicando un patrón de localización en torno a la mayor área urbana de la provincia. En el caso peruano la localización también es intensiva en el departamento más que en la provincia, aunque el volumen de esta migración es muy bajo.

Finalmente, las argentinas tienen un patrón de localización diferente, fluctuando la intensidad entre localizaciones en la provincia más que en el departamento, lo que es compatible con un patrón más disperso en términos de lugares de residencia en la región. Este grupo también experimenta una severa reducción a finales del período.

Con relación a la endogamia neta, los resultados son distintos por nacionalidades: nuevamente las comunidades boliviana y peruana aparecen como extremadamente más endogámicas, en ese orden, y mucho más bajo en el caso de la comunidad argentina. Dado el tamaño de la inmigración boliviana, y su alta masculinización, se podría esperar este resultado, puesto que las mujeres contarían con un importante contingente de varones para encontrar pareja. Del mismo modo, el resultado para el caso peruano es llamativo, pues se trataba de una comunidad muy pequeña, en este caso los niveles de endogamia exhibidos podrían ser indicativos de una estrategia de cierre endogrupal o estrategia separadora. En oposición, el resultado para la comunidad argentina es compatible con una estrategia integradora que privilegia la mixtura por medio de los vínculos matrimoniales.

Con relación a la procedencia geográfica de los inmigrantes, los patrones son concentrados, la mayoría de los grupos proviene de tres o cuatro localizaciones específicas en sus países de origen. En todas las nacionalidades nuevamente los hombres presentan un grado de diversificación relativo mayor comparados con las mujeres. Para ellas este resultado podría indicar que sus procesos migratorios están conectados mediante redes sociales, sean familiares o de amistades. En términos re- 
lativos en esta dimensión, las argentinas presentan una mayor diversidad mientras que las bolivianas una menor. Otra vez este resultado es interesante para el caso de las mujeres bolivianas, puesto que la alta concentración en asociación con el gran volumen de la colonia residente, sumado a la alta masculinización de la misma, generaría condiciones que facilitan la reproducción cultural y la preservación de dispositivos patriarcales, los que potencialmente reducen los espacios de acción de las mujeres no solo en las comunidades de origen, sino también en las comunidades receptoras.

Con relación al patrón de ocupaciones, los indicadores de concentración muestran una perfecta separación entre la situación comparativa de hombres y mujeres. Para ellos existiría una mayor diversificación ocupacional mientras que para ellas la concentración sería mayor en las tres nacionalidades bajo análisis, con una proporción dominante de mujeres dedicadas a las labores tradicionales del cuidado del hogar. No obstante esta situación general, existen variaciones entre los grupos de mujeres que vale la pena destacar. La situación de las argentinas es relativamente más concentrada, tal como se indicaba en posiciones tradicionales como las labores del hogar, pero también en oficios tipo 3D como lavanderas, cocineras y modistas. Las mujeres peruanas presentan una situación de concentración relativa intermedia, mayoritariamente dedicadas a las labores del hogar pero también participando en menor medida como comerciantes o costureras. Por otra parte, la situación de las mujeres bolivianas presenta un grado mayor de diversificación comparadas con sus compañeras peruanas y argentinas. Ellas presentan la menor participación relativa en las labores del hogar, y también participan en un conjunto de ocupaciones de calificación baja a intermedia como jornaleras, modistas/costureras, comerciantes y empleadas.

Finalmente la evidencia respecto de la localización de la migración femenina en proyectos migratorios de tipo familiar (con presencia de hermanos), no encuentra soporte en los datos.

En consecuencia, la migración femenina examinada presenta características similares de inserción incipiente en el mercado laboral, en un ambiente que seguramente restringe a las mujeres a continuar ocupando sus roles tradicionales en sociedad a pesar de las potenciales oportunidades asociadas al proyecto productivo modernizador que se realiza en la provincia de frontera que es la Antofagasta de la época.

\section{* Referencias citadas}

\section{ARCHIVO HISTÓRICO UNIVERSIDAD CATÓLICA DEL NOR-}

TE. Cajas de Prontuarios de Extranjería correspondientes a Bolivia (Cajas 42-78), Perú (Cajas 168-172) y Argentina (Cajas 1-7).

\section{ARCHIVO SERVICIO DEL REGISTRO CIVIL E IDENTIFICA-} CIONES DE ANTOFAGASTA. Libros de Matrimonios años 1885-1930, 44 libros (el correspondiente a 1899 está perdido).

ACEMOGLU, D. y J. ROBINSON. 2012. Why Nations Fail: The Origins of Power, Prosperity, and Poverty. Crown Publishers, New York, NY, USA.

ACUÑA RODRÍGUEZ, O. 2010. A propósito de los cincuenta años del voto femenino. Construcción de ciudadanía en las mujeres. Historia y Espacio, Universidad del Valle, Colombia. Disponible: http://Bibliotecadigital.univalle.edu.co/bitstream/10893/954/1/003\%20ART.pdf (consulta 22.05.2015).

BARRANCOS, D. 2008. Mujeres entre la casa y la plaza. Editorial Sudamericana, Buenos Aires.
BARRANCOS, D. y G. CANO. 2006. Introducción. En Historia de la mujer en España y América Latina. Del siglo XX a los umbrales del $X X I$, pp. 547-556. I. Morant (Dirección) Editorial Cátedra, Madrid.

BARRAGÁN, R. 1997. Miradas indiscretas a la patria potestad: articulación social y conflictos de géneros en la ciudad de La Paz, siglos XVIII-XIX. En Más allá del silencio. Las fronteras de género en los Andes. D. Arnold (Comp.). ILCA/CLASE Research Series núm. 27, tomo I, La Paz, Bolivia.

BÉRTOLA, L. y J. A. OCAMPO. 2013. El desarrollo económico de América Latina desde la independencia. FCE, México.

BÉRTOLA, L. y J. WILLIAMSON. 2003. Globalization in Latin America before 1940. NBER Working Paper 9687, Cambridge. May.

BLAU, P. M., T. C. BLUM \& J. E. SCHWARTZ. 1982. Heterogeneity and intermarriage. American Sociological Review 47: 45-62. 
BOURDIEU, P. 2000. La dominación masculina. Editorial Anagrama, España.

CALLE R., M. 2008. Peruanos, bolivianos y argentinos en Tarapacá según sus pautas matrimoniales. ¿Pluralismo cultural o crisol de razas? 1885-1910. Revista de Ciencias Sociales 21: 29-59.

CASTRO CARVAJAL, B. 1997. La pobreza en Colombia 1886-1930. Estado-Iglesia y Ciudadanía. Ponencia Asociación de Estudios Latinoamericanos. Abril. México. Disponible: www.lasa.international.pitt.edu/LASA97/castro.pdf (consulta 25 mayo 2015).

CERNA BARBA, M., M. V. ESTRADA PÉREZ DE MARTOS y R. M. GODOY SERPA DE FONSECA. 1997. Género y trabajo femenino en el Perú. Rev. Latino-Am. Enfermagem, Ribeirao Preto, abril, 5(2): 23-31.

COSAMALÓN A., J. A. 2011. Población y mercado laboral 18271940. En Compendio de historia económica del Perú, pp.18-90. C. Contreras (Ed.). José Cosamalón, Fernando Armas, José Deustua, Martín Monsalve, Alejandro Salinas (Autores). Banco Central de Reserva de Perú-Instituto de Estudios Peruanos, Lima.

CORTÉS C., R. 1992. El crecimiento de la economía argentina c. 1870-1914. En Historia de América Latina, pp. 9-36. L. Berthel (Ed.), vol. 10 América del Sur c. 1870-1930. Editorial Crítica, Barcelona.

COURTIS, C. y M. I. PACECCA. 2010. Género y trayectoria migratoria: mujeres migrantes y trabajo doméstico en el Área Metropolitana de Buenos Aires. Papeles de Población 16(63): 155-185.

CUERVO, M. 2004. Desarrollo económico y primacía urbana en América Latina. Una visión histórica-comparativa. En El rostro urbano de América Latina. O rostro urbano da América Latina. CLACSO (Eds.). Consejo Latinoamericano de Ciencias Sociales, Buenos Aires, Argentina.

CURRAN, S. y E. RIVERO-FUENTES. 2003. Engendering Migrant Networks: The Case of Mexican Migration. Demography $40(2): 289-307$

DEATON, A. 2013. The Great Escape: Health, Wealth, and the Origins of Inequality. Princeton University Press, Princeton, NJ, USA.

DE LISCIA, M. 2006. Mujeres, familia y salud en Argentina y Chile. En Historia de la mujer en España y América Latina. Del siglo XIX a los umbrales del XX, vol. III, pp. 746-782. I. Morant (Dirección). G. Gómez Ferrer, G. Cano, D. Barrancos, A. Lavrin (Coords.). Editorial Cátedra, Madrid.

DEVOTO, F. y B. FAUSTO. 2004. Argentina Brasil 1850-2000. Un ensayo de historia comparada. Editorial Sudamericana, Buenos Aires.
ESCOBAR, D. 2013. El mercado laboral femenino e infantil en Antofagasta. 1880-1930. Historia 46(2): 343-394.

FLORES, R. A. 2003. La migración femenina en América Latina. México. D.F. Disponible en www.weibiig.sociales.uba.ar/pob. migra./Archivos/Ramiro_Flores/MigraciónFemenina.pdf (consulta 27.01.2016).

FLORES, R. A. (s.d.) El crecimiento de la población argentina. Disponible en www.weibiig.sociales.uba.ar/pob.migra/Archivos/Ramiro_Flores/Crecimiento.pdf. Consulta 27.01.2016.

GALLO, E. 1992. Política y sociedad en Argentina 1870-1916. En Historia de América Latina, pp. 37-66. Leslie Berthel (Ed.), vol. 10 América del Sur c. 1870-1930. Editorial Crítica, Barcelona.

GARCÍA J. A, y S. B. Guardia (Eds.). 2002. Historia de las mujeres en América Latina, vol. 2. Universidad de Murcia, Servicios de Publicaciones.

GOETSCHEL, A. M. 2007. Educación de las mujeres, maestras y esferas públicas. Quito en la primera mitad del siglo XX. FLACSO, Abya-Yala, Quito.

GONZALBO A., P. (Coord.). 1999. Familia y educación en Iberoamérica. El Colegio de México, México.

GONZÁLEZ M., Sergio. 2009. La presencia boliviana en la sociedad del salitre y la nueva definición de la frontera: auge y caída de una dinámica transfronteriza (Tarapacá 1880-1930), Chungara 41(1): $71-81$

GONZÁLEZ P., J. A. 2010. La industria minera de Antofagasta y la inmigración boliviana durante el ciclo salitrero. Notas para su estudio, Si Somos Americanos. Revista de Estudios Transfronterizos X: 97-127.

GONZÁLEZ P., J.A. 2010a. La provincia de Antofagasta. Creación y consolidación de un territorio nuevo en el Estado chileno: 18881933, Revista de Indias, vol. LXX, 249:345-380 mayo-agosto.

GUARDIA, S. B. 1995. Mujeres peruanas: el otro lado de la historia. Ed. Minera, Lima.

HATTON T. J. y J. G. WILLIAMSON. 2006. What determines Immigration's Impact? Compaing Two Global Centuries, NBER Working Paper Series 12414. July.

HERNÁNDEZ, R. 1930. El Salitre (Resumen histórico desde su descubrimiento y explotación). Fisher Hnos., Valparaíso.

ISARD, W. 1971. Métodos de Análisis Regional. Ediciones Ariel, Barcelona, España. 
ISSERMAN, A. M. 1977. The Location Quotient Approach to Estimating Regional Economic Impacts. Journal of the American Planning Association 43(1):33-41.

ITATI P., A. 2006. El acceso de la mujer a la educación universitaria, Revista Argentina de Sociología 4(7): 11-46.

KLAREN, P. 1992. Los orígenes del Perú moderno 1880-1930. En Historia de América Latina, pp. 233-279. L. Berthel (Ed.), vol. 10 América del Sur c. 1870-1930. Editorial Crítica, Barcelona.

KLEIN, H. 1983. La formación del imperio del estaño de Patiño. Historia Boliviana, III/2, pp. 237-252.

KLEIN, H. 1992. Bolivia, desde la guerra del Pacífico hasta la guerra del Chaco 1880-1932. En Historia de América Latina, pp. 204-232. L. Berthel (Ed.), vol. 10 América del Sur c. 1870-1930. Editorial Crítica, Barcelona.

KLEIN, H. 2011. La evolución de la población latinoamericana después de las guerras de independencia. En La cuestión colonial, pp. 537-567. H. Bonilla (Ed.), Universidad Nacional de Colombia, Bogotá.

LAFORTUNE, J. y TESSADA, J. 2012. Smooth(er) Landing? The Dynamic Role of Networks in the Location and Occupational Choice of Immigrants. Economic History and Cliometrics Lab Working Paper \# 14. PUC, Santiago de Chile.

LAGRAVE, R. M. 2000. Una emancipación bajo tutela. Educación y trabajo de las mujeres en el siglo XX, pp. 506-535. En Historia de las mujeres en Occidente. G. Duby, M. Perrot (Dir.). Tomo 5, El Siglo XX. Ed. Taurus Minor, Madrid.

LAMPHERE, L. 1986. From working daughters to working mothers: Production and reproduction in an industrial society. American Ethnologist 13: 118-130.

LAVRIN, A. 1985. Las mujeres latinoamericanas. Perspectivas históricas. FCE, México.

LE FEUVRE, N. 1997. Trabajo y empleo de las mujeres en Europa: La distinción conceptual entre "trabajo" y "empleo". En Las mujeres en la Unión Europea. Disponible: http://www.helsinki.fi/ science/xantippa/wes/wes22 html (consulta 26.05.2015).

LIEVENS, J. 1998. Interethnic marriage: bringing through multilevel modeling. European Journal of Population 14: 117-155.

LOBATO, M. Z. 2013. Las rutas de las ideas: "cuestión social", feminismo y trabajo femenino. Revista de Indias LXXXIII (257): 131-156.
MACDONALD, J. S. \& L. D. MACDONALD. 1964. Chain Migration Ethnic Neighborhood Formation and Social Networks. The Milbank Memorial Fund Quarterly 42: 82-97 (1 Jan).

MANNARELLI, M. E. 1999. Limpias y modernas: género, higiene y cultura en la Lima del Novecientos. Centro de la Mujer Peruana "Flora Tristán”, Lima.

MARICHAL, C. 2011. Crisis financieras y debates sobre la primera globalización: reflexiones desde la historia económica latinoamericana. Mundo Siglo XXI. Revista del CIECAS-IPN 25, vol. VII, pp. 5-14.

MARÍN MUÑOZ, M. DEL R. 2003. Trabajo femenino, política familiar y teorías económicas. Boletín Económico de ICE 2774 (14 al 20 de julio), pp. 5-11.

MARRERO, A. 2006. El asalto femenino a la universidad: un caso para la discusión de los efectos reproductivos del sistema educativo en relación al género. Revista Argentina de Sociología 4(7): 47-69.

MASSEY, D. S., J. ARANGO, H. GRAEME, A. KOUAOUCI, A. PELLEGRINO, \& J. E. TAYLOR. 1993. Theories of International Migration: A Review and Appraisal. Population and Development Review 19(3): 431-466.

MAURO C., A., L. GODOY CATALÁN, X. DÍAZ BERR. 2009. Trabajo y empleo femenino en Chile 1880-2000. Su aporte al desarrollo del país desde la economía doméstica, el trabajo voluntario y el trabajo remunerado. Informe Final. Proyecto FONDECYT Regular 1060057. Santiago de Chile.

MESA, J., T. GISBERT, C. MESA GISBERT. 1998. Historia de Bolivia. Editorial Gisbert, La Paz.

MOINEDDIN, R., J. BEYENE \& E. BOYLE. 2003. On the Location Quotient Confidence Interval. Geographical Analysis 35(3): 249-256.

MOLYNEUX, M. 2000. Women's Movements in International Perspective: Latin America and Beyond. Ed. Palgrave, New York-London.

MONSALVE, M. 2011. Industria y mercado interno 1821-1930, pp. 238-550. C. Contreras (Ed.). Banco Central de Reserva de PerúInstituto de Estudios Peruanos, Lima.

MORA, V. 1993. La mujer obrera en la educación y en el discurso periodístico en Costa Rica (1900-1930). Anuario de Estudios Centroamericanos 19(1): 67-77. 
NORRIS, B. 2001. Ideology and Social Improvement in Bolivia during the zoth Century. Revista de Estudios Bolivianos/Bolivia Studies Journal, vol. 18: 198-228.

OLEN, F. 1999. El mito de la intervención del Estado en la familia, pp. 413-442. En Género y Derecho. A. Facio, L. Fries (Eds.). American University, Washington College of Law-Lom Ediciones-La Morada, Santiago de Chile.

O'ROURKE, K. H. 2004. The Era of Free Migration: Lessons For Today. IISS. Discussion Paper N${ }^{\circ}$ 8. Dublin - Ireland, January.

ORTEGA, L. y H. VENEGAS. 2005. Expansión Productiva y Desarrollo Tecnológico. Chile: 1850-1932. [Expansion of Production and Technological Development. Chile: 1850-1932]. Editorial de la Universidad de Santiago, Santiago de Chile.

PATEMAN, C. 1996. Críticas feministas a la dicotomía público/ privado", pp. 31-52. En Perspectivas feministas en teoría política. C. Castells (Comp.). Ed. Paidós, Buenos Aires, Argentina.

PEDRAZA, Z. 2011. La "educación de las mujeres", el avance de las formas modernas de feminidad en Colombia. Revista de Estudios Sociales 41: 72-83, Bogotá, diciembre.

PERUSO, M. L. (Coord.). 2006. Las mujeres y sus luchas en la Historia Argentina. Editorial Carcos S.R.L., Buenos Aires, Argentina.

PINTO, J. 1990. La Transición Laboral en el Norte Salitrero: La Provincia de Tarapacá y los Orígenes del Proletariado en Chile 1870-1890. Historia 25: 207-228.

PINTO V., J. y V. VALDIVIA ORTIZ DE ZÁRATE. 1994. Peones chilenos en tierras bolivianas: la presencia laboral chilena en Antofagasta 1840-1879. Población \& Sociedad. Revista Regional de Estudios Sociales 2: 103-132.

PIORE, M. J. 1979. Birds of Passage: Migrant Labour and Industrial Societies. Cambridge University Press, Cambridge.

PIZZOLITO, G. 2006. Distribución de la población y migraciones interiores en Argentina: sus determinantes individuales y regionales. Facultad de Ciencias Económicas. Universidad de La Plata. Diciembre.

RAMOS ESCANDÓN, C. 1984. Las mujeres latinoamericanas: generación de datos y metodología para investigación futura. Disponible en http://secuencia.mora. edu.mx/index.php/Secuencia/.../3181 (consulta 22.05.2015).

RECCHINI de LATTES, Z. y A. LATTES. 1974. La población de Argentina. World Population Year. Cicred. Series.
RHOADES, S. A. 1993. The Herfindahl-Hirschman Index. Federal Research Bulletin 79: 188 -190.

RODRÍGUEZ LEYTON, N. 2007. Discurso y cultura urbana libertaria en la primera mitad del siglo XX. El discurso anarquista-individualista en el semanario Arte y Trabajo (Ciudad de Cochabamba 1921-1934). En El espacio urbano andino: escenario de reversiones y reinversiones del orden simbólico colonial. R. Rodríguez Márquez, M. Villena Alvarado (Coords.). Estudios Bolivianos 13: 217-296.

ROJAS D. M. 2012 [1883]. El Desierto de Atacama y el territorio reivindicado. Biblioteca Fundamentos de la Construcción de Chile. Dirección de Bibliotecas y Museos - Pontificia Universidad Católica de Chile - Cámara Chilena de la Construcción, Santiago de Chile.

SAGREDO, R. y C. GAZMURI. 2006. Historia de la vida privada en Chile. Tomo II: El Chile moderno de 1840 a 1925. Aguilar Chilena de Ediciones, Santiago de Chile.

SÁNCHEZ A., B. 2007. The other europeans: immigration into Latin America and the International Labour Market (1870-1930). Journal Iberian and Latin America Economy History, año XXV, invierno, 3: 395-426.

SÁNCHEZ ALBORNOZ, N. 2004. The Population of Latin America. A History. Berkely: University of California Press, Berkeley, CA, USA.

SÁNCHEZ-DOMÍNGUEZ, M. 2011. Exogamia matrimonial de inmigrantes latinoamericanos con españoles: integración o estrategia migratoria. Revista Latinoamericana de Población 5: 33-62 (8 junio).

SCOTT, J. 1987. On language, Gender and Working-Class History. International Labor and Working-Class History 31: 1-13, Spring.

SICOTTE, R. C. VIZCARRA \& K. WANDSCHNEIDER. 2009. The fiscal impact of the War of the Pacific, Cliometrica 3: 97-121.

SOLBERG, C. 1970. Inmigration and Nationalism: Argentina and Chile, 1890-1914. University of Texas Press, Austin.

SOLIZ S., A. S. 2014. Crecimiento y distribución espacial de la población de Bolivia. Parity CB Consultores Bolivianos, La Paz.

SORUCO SOLOGUREN, X. 2012. La ciudad de los cholos. Mestizaje $y$ colonialidad en Bolivia, siglos XIX y XX. IFEA, La Paz. Segunda Edición.

TAPIA, M. 2012. Frontera y migración en el norte de Chile a partir del análisis de los censos de población. Siglos XIX- XXI. Revista de Geografía Norte Grande 53: 177-198. 
TAPIA, M. 2014. Bolivia, historia de migraciones: pasado y presente. En Las migraciones bolivianas en la encrucijada interdisciplinar: evoluciones cambios y tendencias, pp. 9-29. C. Solá, S. Parella, A. Petroff (Coords.). Focus in International Migration 1. Universitat Autónoma de Barcelona, Servei e Publicaciones, Barcelona.

VALLE FERRER, N. 2004. Anarquismo y feminismo: la ideología de cuatro mujeres latinoamericanas de principios del siglo XX, Revista Cultura. Instituto de Cultura Puertorriqueña, San Juan de Puerto Rico, junio, pp. 91-99.

VAN DEUSEN, N. E. 2002. Voces y silencios: el género en la historia peruana (1977-2002). Historia XXVI (1-2): 125-186.

WILLIAMSON, J. G. 2002. Land, Labor, and Globalization in the Third World, 1870-1940. The Journal of Economic History 62(1): 55-85.

\section{Notas finales}

La apreciación de esta narrativa de la industrialización histórica no es necesariamente única, existen posiciones críticas que revalorizan el siglo XVI y la expansión imperialista desde Europa hacia el resto del mundo como momento clave para el desarrollo de una globalización y expansión del sistema capitalista. En este mismo sentido, Deaton (2013) plantea una completa visión alternativa centrada en reconocer las condiciones económicas preexistentes, en los diferentes territorios mundiales, al proceso de industrialización iniciado en 1750 . En la etapa siguiente, que terminaría en 1945, él otorga fundamental importancia a los procesos de generación y acumulación de riquezas y cómo ellos impactan en las condiciones de bienestar material, social, en salud, esperanza de vida y también en el bienestar subjetivo de las personas, todas condiciones que han mejorado a partir del 1945 a la actualidad. Estas ideas también serían compatibles con la llamada economía institucional, donde se sostiene el rol de las instituciones, políticas, sociales y culturales en la explicación de cómo las diversas sociedades se desarrollan económicamente (Acemoglu y Robinson 2012). En este enfoque las condiciones históricas tienen un impacto insospechado en las trayectorias de crecimiento y desarrollo de largo plazo de las sociedades humanas. 
